UC-80 Reactors - General

(TI-4500, 15th Ed.)

Contract No. W-7405-eng-92

\title{
HAZARDS SUMMARY REPORT FOR THE VMR CRITICAL-ASSEMBLY EXPERIMENTS
}

\section{by}

Richard A. Egen

William S. Hogan

David A. Dingee

Joel W. Chastain

June 10, 1960

\section{BATTELLE MEMORIAL INSTUTUTE $505 \mathrm{King}$ Avenue Columbus 1, Ohio}




\section{DISCLAIMER}

This report was prepared as an account of work sponsored by an agency of the United States Government. Neither the United States Government nor any agency Thereof, nor any of their employees, makes any warranty, express or implied, or assumes any legal liability or responsibility for the accuracy, completeness, or usefulness of any information, apparatus, product, or process disclosed, or represents that its use would not infringe privately owned rights. Reference herein to any specific commercial product, process, or service by trade name, trademark, manufacturer, or otherwise does not necessarily constitute or imply its endorsement, recommendation, or favoring by the United States Government or any agency thereof. The views and opinions of authors expressed herein do not necessarily state or reflect those of the United States Government or any agency thereof. 


\section{DISCLAIMER}

Portions of this document may be illegible in electronic image products. Images are produced from the best available original document. 
ABSTRACT.$\cdot \cdot \cdot \cdot \cdot \cdot \cdot \cdot \cdot \cdot \cdot \cdot \cdot \cdot \cdot \cdot \cdot \cdot \cdot \cdot \cdot$.

INTRODUCTION • . . . . . . . . . . . . . . . . . 1

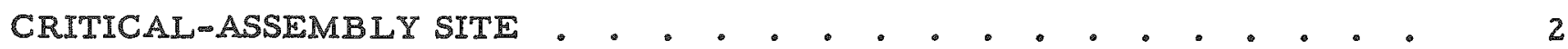

Site Location and Description . . . . . . . . . . . . 2

Critical-Assembly Building. . . . . . . . . . . . . . 6

Assembly Room . . . . . . . . . . . . . . 6

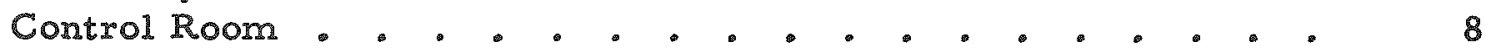

Storage Vault . . . . . . . . . . . . . . . 8

Counting Room. . . . . . . . . . . . . . . . . 8

Radiation-Instrument Calibration Room. . . . . . . . . 8

Office and Laboratories . . . . . . . . . . . . . . 8

Safety Equipment . . . . . . . . . . . . . . . 9

Makeup of Surrounding Area . . . . . . . . . . . . . 9

Population Distribution . . . . . . . . . . . . . . . 9

Industry Adjacent to the Site . . . . . . . . . . . . . 10

Seismology . . . . . . . . . . . . . . . 10

Climatology . . . . . . . . . . . .... 10

Geology and Hydrology . . . . . . . . . . . . . . 12

DESCRIPTION OF THE POWER REACTOR AND CRITICAL ASSEMBLY . . . 13

The Power Reactor . . . . . . . . . . . . . . . 13

The Critical Assembly . . . . . . . . . . . . . . . 13

CONTROL AND SAFETY MECHANISMS . . . . . . . . . . . . 20

Control and Safety Blades . . . . . . . . . . . . . 20

Startup Source. . . . . . . . . . . . . . . . . . 22

Liquid-Level Control. . . . . . . . . . . . . . . . . . 22

Control and Research Instrumentation . . . . . . . . . . . . 24

Safety and Interlocking System. . . . . . . . . . . . . . 24

SPECIAL CHARACTERISTICS OF THE VMR-CA . . . . - . . . . . 27

Criticality of a Typical Core . . . . . . . . . . . . 27

Reactivity Coefficients . . . . . . . . . . . . . . 30

PLAN OF NORMAL OPERATION . . . . . . . . . . . . . 30

General Limitations on Experiments . . . . . . . . . . . 33

Control Limitations . . . . . . . . . . . . . 33

Power Limitations . . . . . . . . . . . . . . . . 33

Limitations on Core Assembly Operations. . . . . . . . . 33

Precritical Operation Checkout . . . . . . . . . . . . 34

Experiments and Procedures . . . . . . . . . . . . . . . 34 
Criticality Studies

Reactivity-Coefficient Measurements

Activation Measurement

Optimization of Design

Processing and Disposal of Radioactive Materials and Solutions

Hazards During Normal Operation . . . . . . . . . . . 38

Direct Radiation . . . . . . . . . . . . . . . 38

Handling Irradiated Fuel . . . . . . . . . . . . . 38

Fission-Product Hazards . . . . . . . . . . . . . . 38

Accidental Reactivity Additions . . . • . . • . . . . . . . 39

Continuous Addition of Reactivity. . . . . . . . . . . . 39

Accidental Flooding of the Coolant Region . . . . . . . . . 39

Dropping an Object Into the Critical Reactor. . . . . . . . 39

Coolant Mixing Problem. . . . . . . . . . . . . . 40

ACCIDENT ANALXSIS . . . . . . . . . . . . . . . . . . . . 40

Maximum Accident . . . . . . . . . . . . . . . . 40

Core-Temperature Considerations . . . . . . . . . . 43

Discussion and Results of the Accident . . . . . . . . . . . . 47

REFERENCES . . . . . . . . . . . . . . . . . . . . . . . . . 47

APPENDIX A

LETTERS ON EARTHQUAKES.

APPENDIX B

METEOROLOGY REPORT

$B-1$

APPENDIX C

CONCLUSIONS OF GEOLOGY AND HYDROLOGY REPORT .

APPENDIX D

COMMENTS ON THE USE OF FUREURYL ALCOHOL AND FURFURAL IN CRITICAL-ASSEMBLY RESEARCH

$\mathrm{D}-1$

APPENDIX E

OPERATIONAL AND LABORATORY RULES

APPENDIX F 


\title{
HAZARDS SUMMARY REPORT FOR THE VMR CRITICAL- ASSEMBLY EXPERIMENTS
}

\author{
Richard A. Egen, William S. Hogan, \\ David A. Dingee, and Joel W. Chastain
}

\begin{abstract}
Critical experiments are described for the Variable Moderator Reactor (VMR), a reactor concept under investigation by American-Standard for the $A E C$. The VMR is light-water moderaied and cooled and is fueled with slightly anriched uranium dioxide pellets loaded into aluminum tubes. The core consists of 37 hexagonal fuel cans each loaded with 61 fuel pins. The cooling water, which flows upward around the pins inside the fuel can, boils in passing through the core. Reactor control in the prototype will be achieved by varying the moderator height.
\end{abstract}

The site, laboratory, and the critical assembly, including control and safety mechanisms, are described in detail. Special characteristics of the assembly pertinent to safety have been calculated. The nuclear energy released and the average and maximum fuel temperatures resulting from step reactivity increases up to 2 per cent $\Delta d / l_{i}$ are presented in graphical form for two cases. In the first case, fuel-temperature effects are considered to be the only shutdown mechanism; in the second radiolytic gas is considered to contribute to shutdown, in addition to fueltemperature effects.

The accident considered to be the maximum credible accident causes a step addition in reactivity of 1.5 per cent $\Delta k / k$. The nuclear-energy release is between 160 and 310 megawatt-sec depending on the assumed shutdown mechanisms. This accident does not cause any fuel to be vaporized (and probably none to be melted) and, hence, there does not appear to be a hazard from fission-product activizy.

It appears that this critical-assembly program con be conducted with reasonable assurance of safe operation and that no public persons will be jeopardized by its operation.

\section{INTRODUCTION}

The Advanced Technology Laboratories (ATL) of the American-Standard Corporation are evaluating technical feasibility and economic potential of the Variable Moderator Reactor (VMR) concept. This reactor will be water moderated and cooled; the coolant water will boil as it flows upward through the core. The coolant and moderator regions will be separated by fuel-element cans which contain uranium dioxide pins. Reactor control will be achieved by varying the height of the moderator.

Many unique features of this reactor concept, suchas high steam voidage in the coolant region, nonuniformity of the fuel lattice, and variations in moderator height, make it difficult to analyze. To perform the precise analysis required to assess economic potential, ATL is preparing a digital-computer code, PUREE. Critical-assembly studies will be conducted to verify the assumptions and methods used in developing this code.

Battelle has facilities and technical manpower to undertake these investigations and has been requested by ATL to perform the experiments. A Hazards Summary Report which evaluated the Battelle site and facility was submitted and a presentation made to the Advisory Committee on Reactor Safeguards in October, 1954. Reports summarizing the hazards associated with three critical-assembly studies have been submitted and approved 
since that time. These studies include a beryllium-moderated and -reflected reactor described in BMI-ACRS -611 , a plastic-moderated critical assembly described in BMIACRS-615, and a gas-cooled and water-moderated critical assembly described in BMI1240 (Rev.) and BMI-1379. This report presents the hazards considerations pertinent to the critical experiments for the VMR.

The critical-assembly core will be composed of 37 or 61 hexagonal fuel-element cans containing either 61 or 37 aluminum-clad $\mathrm{UO}_{2}$ fuel pins. Adjacent cans will be separated by about 1 in. and this space will contain moderator water. Light water, furfuryl alcohol, and furfural will be used to duplicate various hydrogen densities to simulate boiling in the coolant region. The nominal core diameter will be 4 ft and the fuel length will be $4 \mathrm{ft}$. The assembly will be controlled by coarse and fine vertically acting poison blades and by varying liquid levels. Shutdown safety is provided by poison blades and by emptying moderator and coolant liquids from the reactor tank. A more detailed description of the critical assembly is given in later sections of this report.

The research program will provide data to verify or correct calculational techniques. Hence, the critical assembly will not be an engineering mock-up of the VMR power reactor, and all experiments will be run near atmospheric conditions.

\section{CRITICAL-ASSEMBLY SITE}

Site Location and Description

The site of the Critical-Assembly Laboratory is in Madison County, Ohio, 15 miles west from downtown Columbus. The property is located on the Georgesville-Plain City Road, an improved county highway which is not heavily traveled. The Battelle-owned land extends slightly beyond the Pennsylvania Railroad to the south and is bounded on the east by Big Darby Creek, which is the boundary between Franklin and Madison Counties. The tract contains a total of 694 acres. Figure 1 is a topographic map showing the site in relation to Columbus and the surrounding a rea.

The Critical-Assembly Laboratory is one of four buildings at the Battelle Nuclear Research Center, which is located at the northern end of this property. The location of these buildings with respect to each other and the details of the immediate vicinity are shown in Figure 2. Figure 3 is an aerial photograph of the area and shows a portion of the Battelle land. * The Critical-Assembly Laboratory is labeled ZPR. The nearest boundary of the property is over 1200 ft from the building.

The surrounding area is a farming community and is sparsely populated. The closest town is West Jefferson, population 2500, which is about 2 miles southwest of the laboratory location. The closest building is a barn, $2000 \mathrm{ft}$ northwest of the site, and the closest dwelling is 3100 ft to the southwest. During the summer months, a Girl Scout camp located across the Big Darby is inhabited. The site is about 2000 ft from the camp. The estimated total number of residents within 1 mile of the site is 60 .

The site is located on level ground having an average elevation of $900 \mathrm{ft}$ above sea level. The average elevation of downtown Columbus is approximately 750 it. The change

\footnotetext{
This photograph was taken in 1955 and does not show tecent additions which appear in Figure 2.
} 


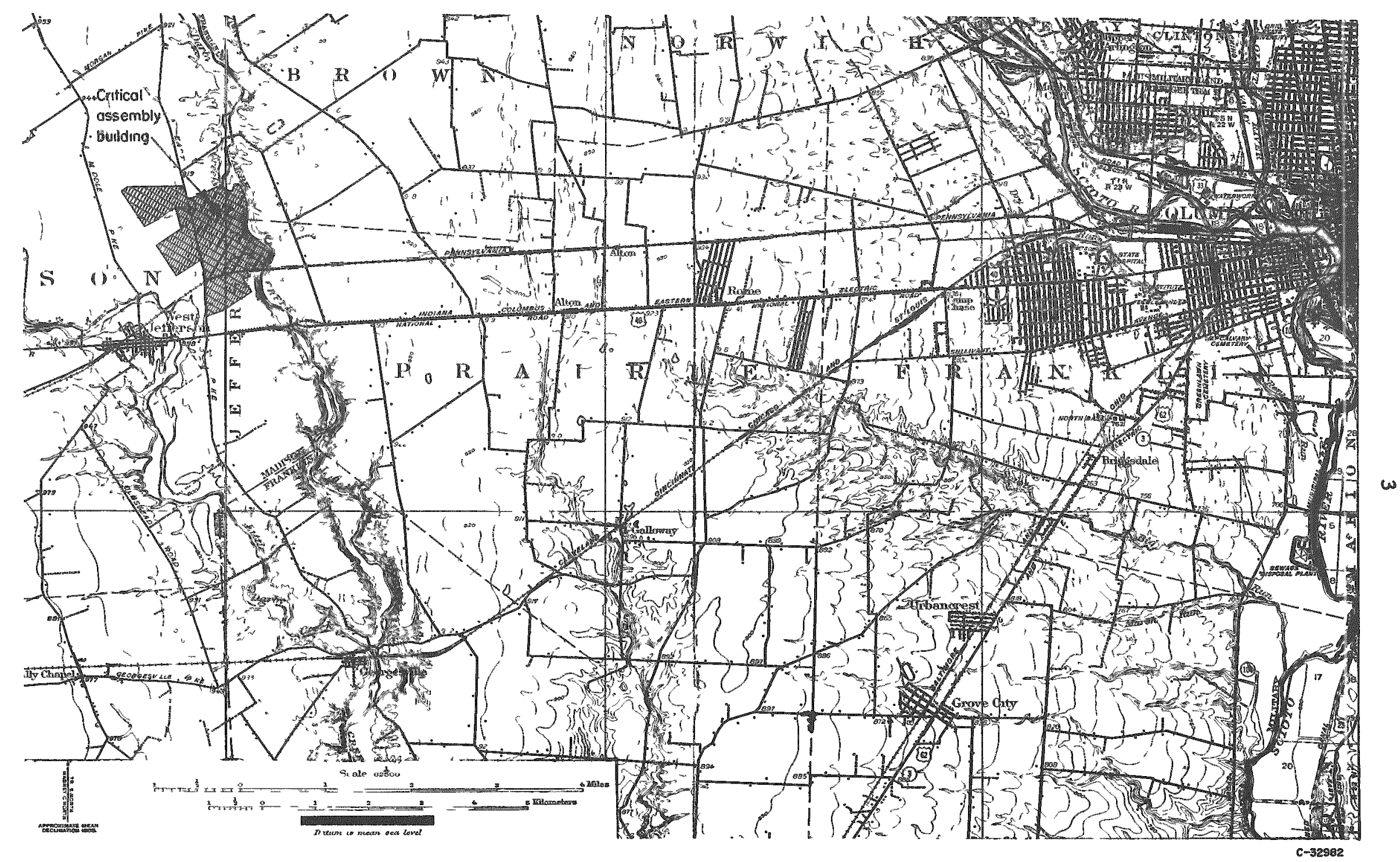

FIGURE 1. TOPOGRAPHCAL MAP 


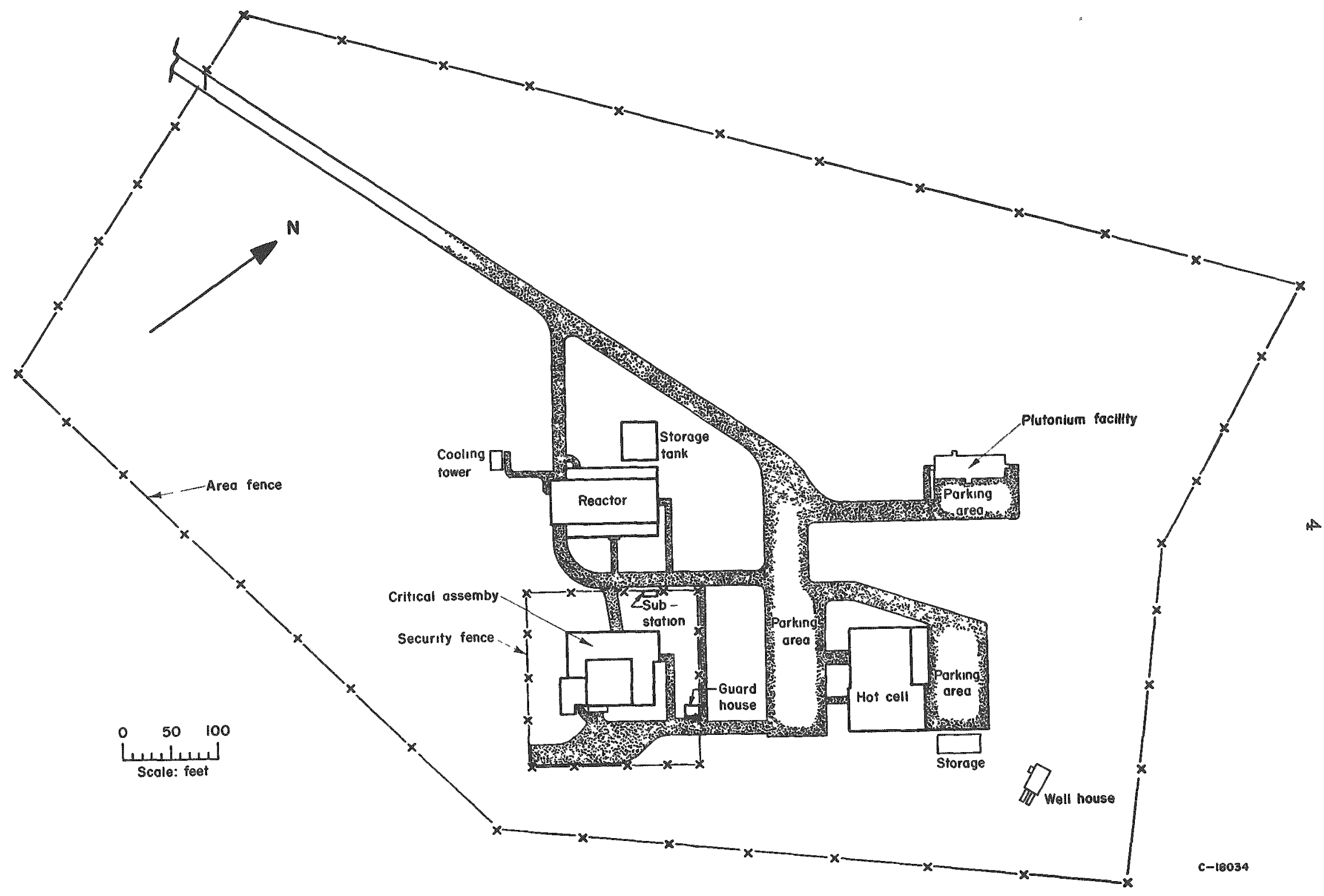

FIGURE 2. BATTELLE NUCLEAR RESEARCH CENTER 


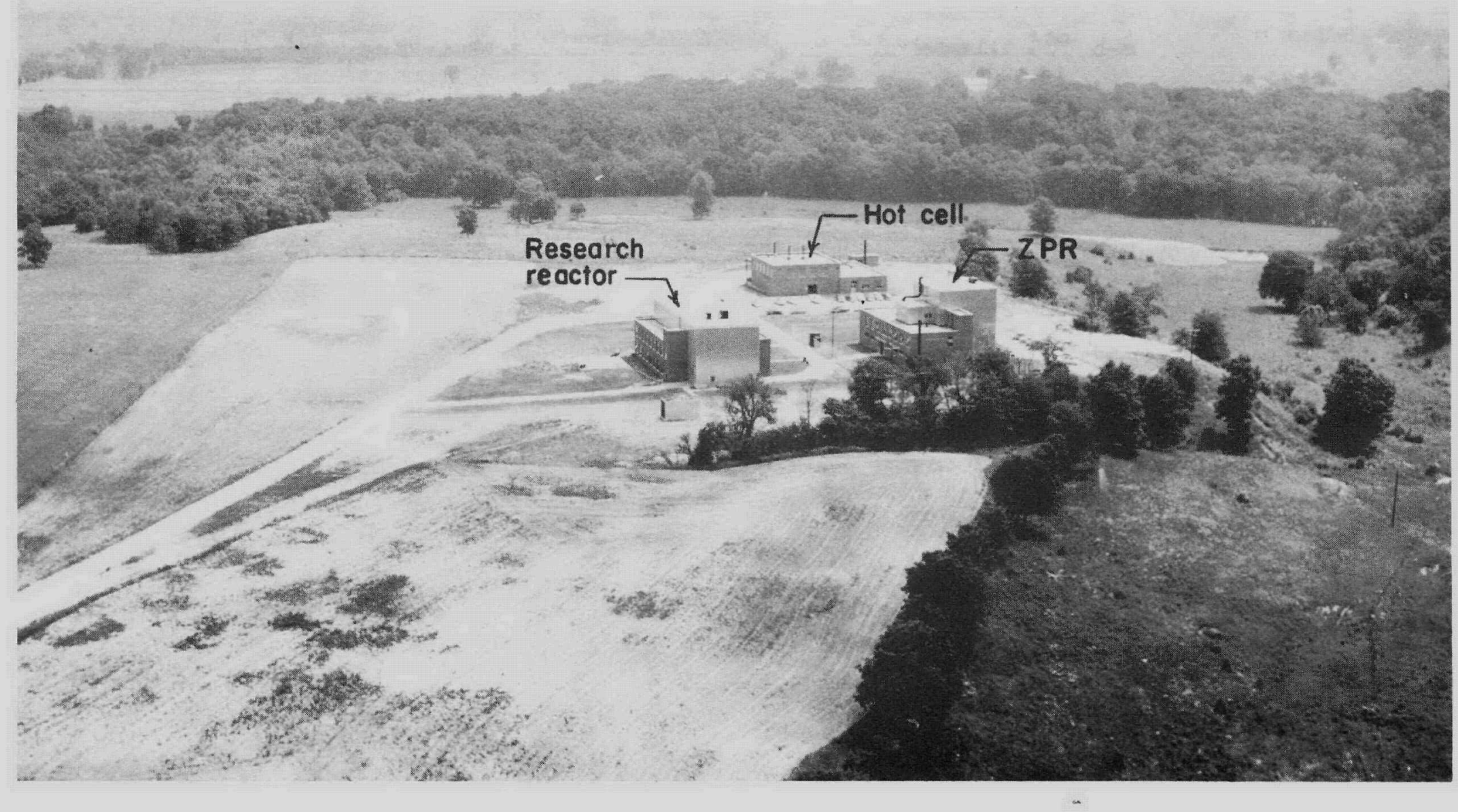

FIGURE 3. AERLAL PHOTOGRAPH OF BATTELLE NUCLEAR RESEARCH CENTER 
in elevation from the site to downtown Columbus takes place by a gradual fall over the 15-mile interval. A flat-bottom ravine about 40 ft deep crosses the plot from east to west and is the bed of a small intermittent stream. The Big Darby Creek flows in a broad valley along the eastern boundary of the property and is approximately 50 ft below the elevation of the site.

\section{Critical-Assembly Building}

The Critical-Assembly Laboratory is a building having $11,430 \mathrm{ft}^{2}$ of floor space. The building contains the reactor-assembly room, a control room, a vault, a counting room, an instrument laboratory, a shop, a radiation-instrument calibration facility, and rooms which may be used as offices or laboratory space. The first-and second-floor plans are shown in Eigure 4. The building is constructed of concrete block faced with brick, with a structural-steel frame, except for the storage vault and assembly room. The storage vault is constructed entirely of reinforced poured concrete. The assemblyroom walls are $2 \mathrm{ft}$ thick up to a height of $26 \mathrm{ft}$. The wall above this and the roof are Qpanel aluminum siding. All of this is supported by a heavy structural-steel frame.

The arrangement of the assembly room, control room, and vault, and the associated stairwell, forms an area which can be shut off from the rest of the building.

The power provided for the installation is $300 \mathrm{kva}$. Other utilities are compressed air, demineralized water, natural gas, and a 3-in. wate - -supply main.

The building is heated by forced-hot-water heat. The temperature is controlled by thermostats in the assembly room and by valves on the individual heaters in other locations. The control room, the instrument laboratory, and the counting room are air conditioned.

\section{As sembly Room}

The reactor assembly room is approximately 40 -ft square and $50 \mathrm{ft}$ high. The three walls facing into the building are of reinforced poured concrete 2 ft thick. The other wall is 1 -ft-thick poured concrete. This concrete extends to a height of $26 \mathrm{ft}$, which is enough to shield personnel in the inhabited portion of the building. Above this height, the walls are constructed of Q-panel aluminum metal siding on the outside and steel sheets on the inside. The $\mathrm{Q}$-panels have caulking material between them. The steel plates have lead tapes sealing the seams. This type of construction furnishes a tight enclosure. The siding above the solid concrete wall is supported by structural-steel framework, which also supports a 10-ton crane. The roof is built up of asphalt and gravel over heavy building paper and is supported by a $Q$-panel metal deck.

A large exhaust fan located in a penthouse above the office area supplies fresh air to the room. The exhaust is through the ceiling. Both the air inlet and the exhaust opening are equipped with louvers and a solenoid-operated sheet-metal plate to make the openings tight when the fan is not in operation. 


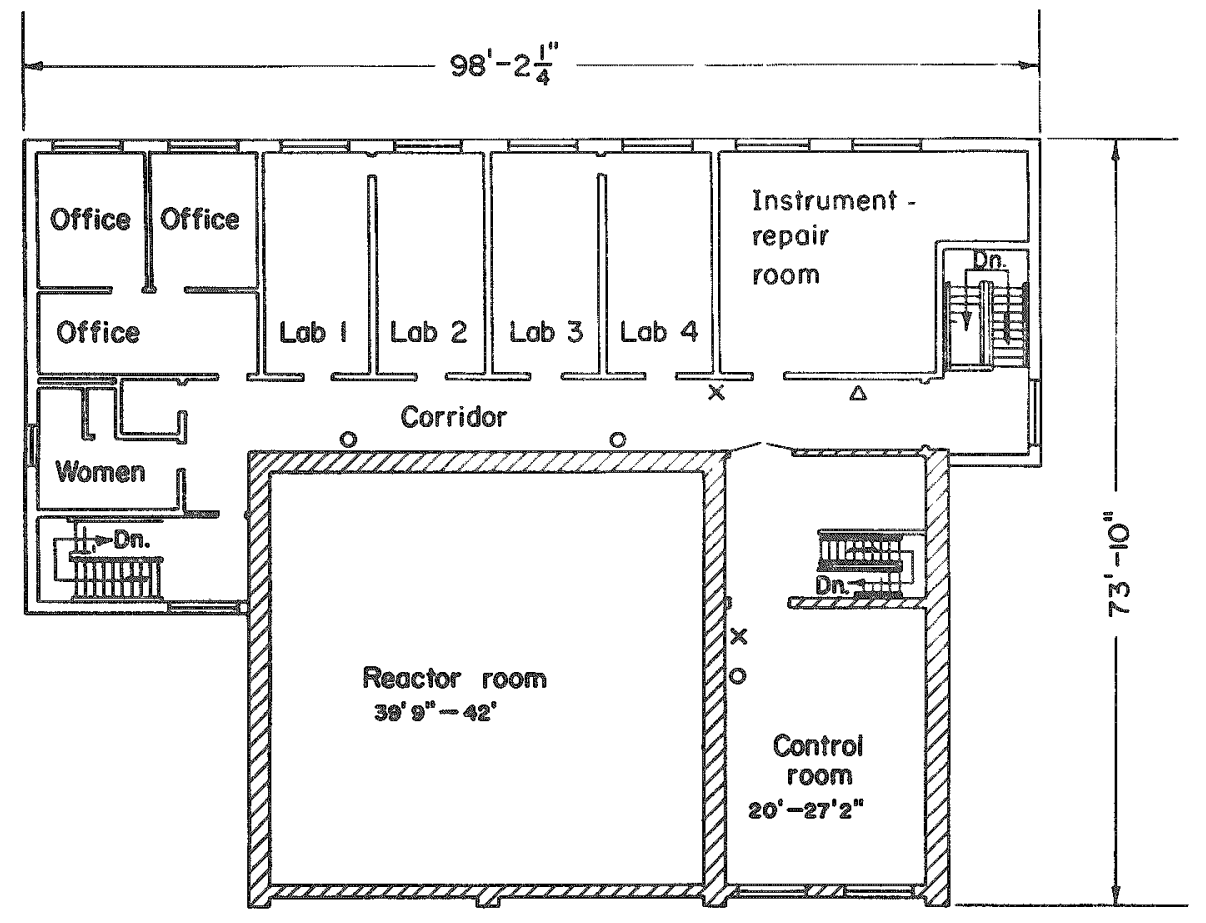

Second Floor Plan

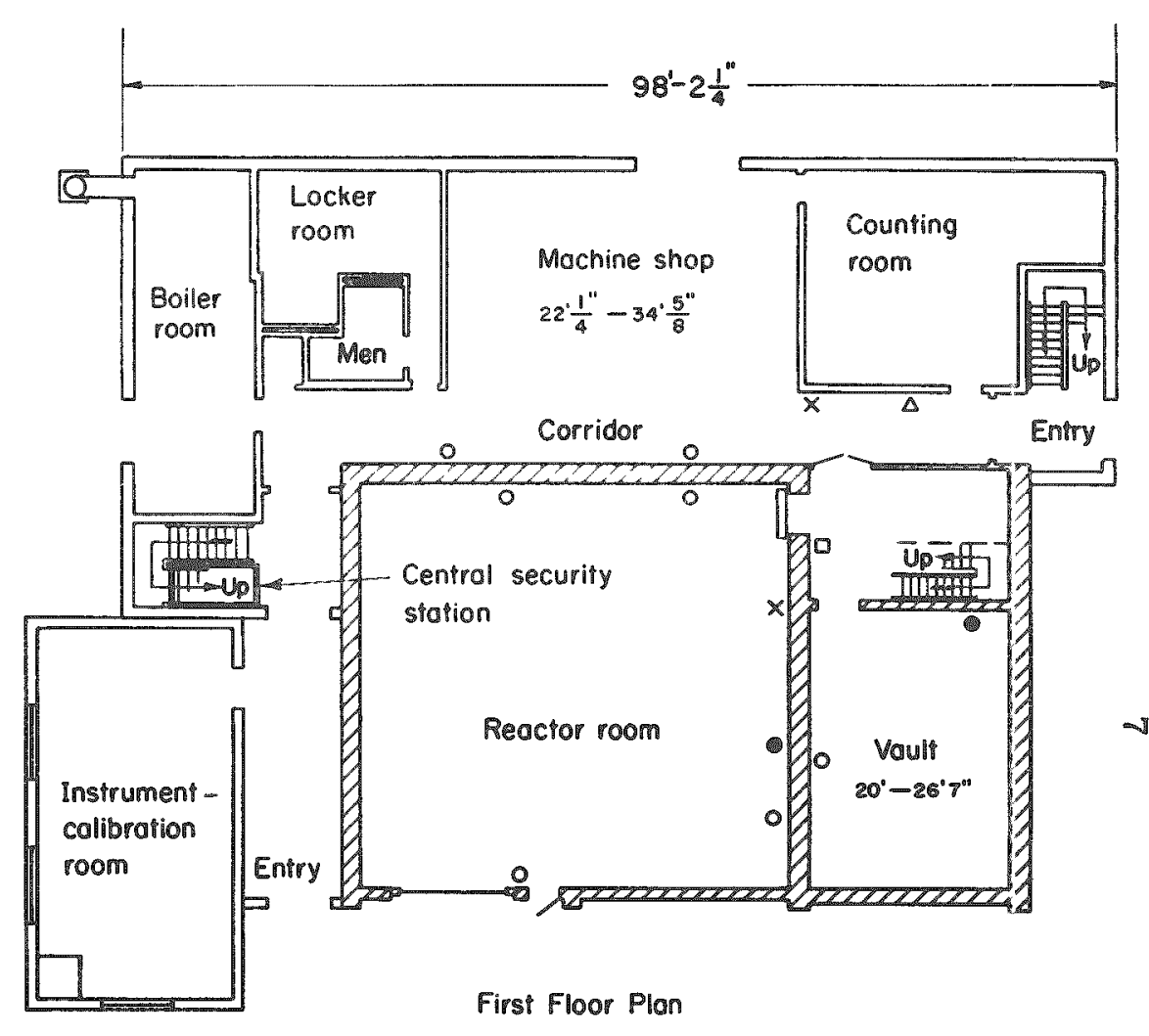

- G-I powder

$\Delta$ Fire hose

- Areo alarm defector

C-32981 
The assembly room has a single entrance into the remaining part of the building which can be closed off with a steel and concrete door having gamma-shielding properties equivalent to the 2-ft wall. In addition to this door, there is a personnel entrance and a truck entrance to the outside which is kept closed and locked during reactor operations.

There are a number of 4 -in. conduit openings between the assembly room and control room for the passage of control wiring. These openings are at a $45-\mathrm{deg}$ angle above head height to prevent radiation streaming from the openings from reaching personnel. The openings which are rot in use are fitted with shielding plugs.

Control Room

The control room is located on the second floor adjacent to the assembly room. It is approximately $20 \mathrm{ft}$ wide and $27 \mathrm{ft}$ long. Services in this room include air conditioning and a dehumidifier. The control and research instrumentation is located along one wall.

\section{Storage Vault}

The storage vault is on the first floor beneath the control room and is approximately the same size, that is, 20 by $27 \mathrm{ft}$. The walls, floor, and ceiling are of reinforced-concrete construction. Two walls, the floor, and ceiling are l-ft-thick reinforced concrete. The remaining two walls are 2 -it-thick concrete. The steel vault-type door is equipped with a four-tumbler manipulation-proof combination lock.

\section{Counting Room}

The counting room is located on the first floor so that the use of heavy shielding is not a problem and so that foils of short half-life can be removed from the assembly room to the counting room with a minimum delay. The room is approximately $21-f t$ square. No special wall construction is provided and shielding is provided for individual detectors as required. There is a grounded bus bar running around the room. Air conditioning is provided to maintain the air at $75 \mathrm{~F}$ and 50 per cent relative humidity.

Radiation-Instrument Calibration Room

The calibration room adjoins the Critical-Assembly Laboratory. It is a concreteblock brick-faced room with about $950 \mathrm{ft}^{2}$ of work space. It houses laboratory space and special nuclear sources which are used for calibrating the radiation-safety instrumentation in operation at Battelle's Nuclear Energy Center.

Office and Laboratories

Approximately $750 \mathrm{ft}^{2}$ of floor space is provided on the first floor for a machine shop. Equipment in this shop includes a power hacksaw, a band saw, a lathe, a drill press, a milling machine, a number of benches, and an assortment of hand tools. The machine shop has a truck entrance for bringing in bulky equipment. 
An electronic laboratory for repairing instruments and for building up and modifying the instruments as required is located on the second floor above the counting room. This laboratory is air conditioned.

Seven additional rooms on the second floor provide space for offices, for a conference room, and for laboratory space, should it be required.

\section{Safety Equipment}

Fire-control and radiation-monitoring and safety equipment is located in the building as shown in Figure 4. The fire-control equipment is concentrated in areas having any probability of accidential fire.

The corridor and room radiation detectors are film badges which are sensitive to gamma and beta rays and neutrons. Two area alarm-monitors are in operation at points where accidental criticality is possible; that is, where fuel is stored or assembled. In the fuel storage vault the alarm-monitor is a commercial instrument, trade name Gammalarm. In the critical-assembly room one of the reactor instruments, the scintillation crystal, serves in a dual capacity. When the reactor is not operating it is an alarm-monitor. During operations it is part of the normal reactor safety system.

Makeup of Surrounding. Area

The location of the site and a brief description of the geography of the region was given above. The sections below discuss other features of the area with emphasis on factors which may be related to the operation of the critical facility.

Population Distribution

The population distribution at various radii from the site was obtained, for the most part, from the Chamber of Commerce 1954 statistics and the State-Wide Highway Planning Survey, 1953. The distribution of population at various distances from the site is shown in Table 1.

TABLE 1. POPULATION DISTRIBUTION WITHIN VARIOUS DISTANCES FROM SITE

\begin{tabular}{cr}
\hline Distance Radius & Population \\
\hline $1500 \mathrm{ft}$ & 0 \\
$2500 \mathrm{ft}$ & 0 \\
1 mile & 60 \\
2 miles & 1,150 \\
5 miles & 5,100 \\
10 miles & 43,000 \\
\hline
\end{tabular}


Industry Adjacent to the Site

The nearest industry is more than 2 miles from the site. Most of the industries employ less than 100 people: Westinghouse Electric Corporation and the General Motors Corporation, both 8 miles from the site, employ about 4400 and 4000 , respectively. The information regarding adjacent industries is presented in Table 2.

Lincoln Village, a housing project, is located 8 miles from the site. The village has a population of approximately 500 families.

Seismology

In determining the earthquake probability of a given area, all that can be done is to examine the earthquake history of that vicinity and then conjecture that future earthquakes are more likely to occur in places where there have been previous ones.

Several areas in western Ohio have suffered minor earthquake damage. There is no record of earthquakes having occurred in West Jefferson, Ohio, and the immediate vicinity. The nearest seismic activity in recent years was recorded in 1937 in the Anna, Ohio, proximity, which is over 50 miles from the proposed reactor site.

The information on western Ohio earthquakes was obtained in 1954 from Reverend V. C. Stechschulte, Xavier University, Cincinnati, Ohio, and from the U. S. Coast and Geodetic Survey. Letters from the se two sources are included in Appendix A.

Climatology

The climate in the Columbus area is definitely temperate and continental in character. The normal mean daily temperature for June, July, and August is $73.3 F$, although $90 \mathrm{~F}$ or higher is expected about 20 times per year. During the months of December, January, and February, the normal seasonal temperature is $31.2 F$ with three subzero nights per winter average.

The primary prevailing-wind direction is from the southerly quadrant $(41$ per cent of the winds blow from the general direction SE to SW/. The secondary prevailing-wind direction is from the NW. The average wind speed is $8.4 \mathrm{mph}$ with 59 per cent of the winds occurring in the 4 to $12-\mathrm{mph}$ interval. No large seasonal or diurnal variation exists in either the direction or speed of the winds. During a 51 -year periodin Columbus, peak wind speeds have been observed to exceed $51 \mathrm{mph}$ in every month of the year. The maximum recorded speed was $84 \mathrm{mph}$ occurring in July.

Rainfall, averaging nearly 3-1/2 in. per month, is quite evenly distributed from April to August. The record single day's rain was 3.87 in. in July, 1957. The bulk of the summer rainfall comes in frequent thunderstorms, and tornadoes are not unknown. However, local storm records show that only four tornadoes have occurred in the Columbus area since 1931.

Since Ohio is located in the path of many winter storms, Columbus receives a generous amount of cold-season precipitation. The bulk of it comes in the form of rain, but the average winter will yield a total of $22 \mathrm{in}$. of snow. This is quite variable and, in the largest snowfall of recent times, in 1950, 7.5 in. fell in 1 day. 
TABLE 2. INDUSTRIES WITHIN.A 10-MILE RADIUS OF REACTOR FACILITY SITE

\begin{tabular}{|c|c|c|c|}
\hline Industry & Products & $\begin{array}{l}\text { Number of } \\
\text { Employees (a) }\end{array}$ & $\begin{array}{l}\text { Distance } \\
\text { From } \\
\text { Site, miles }\end{array}$ \\
\hline $\begin{array}{c}\text { Ternstedt, Columbus } \\
\text { Division, GMC }\end{array}$ & Auto parts & 4000 & 8 \\
\hline $\begin{array}{l}\text { Westinghouse Electric } \\
\text { Corporation }\end{array}$ & Refrigerators, appliances & 4400 & 8 \\
\hline $\begin{array}{l}\text { Janitrol Aircraft Div. } \\
\text { Surface Combustion } \\
\text { Corporation }\end{array}$ & Aircraft parts & 500 & 8 \\
\hline Rexall Drug Company & Warehouse & 70 & 8 \\
\hline Hartley Newspapers & Printing and publishing & 70 & 10 \\
\hline $\begin{array}{l}\text { Fisher Cast Steel } \\
\text { Products, Inc. }\end{array}$ & Steel castings & 30 & 2 \\
\hline Ohio Seed Company & seed processing & 20 & 2 \\
\hline H. J. Uppeman \& Sons & Lumber & 24 & 9 \\
\hline $\begin{array}{l}\text { West Jefferson Sand and } \\
\text { Gravel Company }\end{array}$ & Sand and gravel & 15 & 3 \\
\hline $\begin{array}{l}\text { Murray Lumber and } \\
\text { Grain Company }\end{array}$ & Elevator, lumber & 10 & 2 \\
\hline $\begin{array}{l}\text { Merriman Cement } \\
\text { Products, Inc. }\end{array}$ & Cement blocks & Less than 10 & 2 \\
\hline Hartco Printing Co. & Painting & Less than 10 & 2 \\
\hline
\end{tabular}

(a) December, 1959. 
Climatology data abstracted from a report prepared by the Scientific Division of the U. S. Weather Bureau are given in Appendix B.

Geology and Hydrology

The principal glacial deposits at the surface in the Battelle site area consist of till and outwash which accumulated as the Wisconsin ice sheet of the Pleistocene Age receded. The till, an unstratified matrix of clay containing rock fragments, underlies the Battelle site to depths ranging from approximately 60 to 200 ft. The outwash, composed of stratified layers of sand and gravel, is thin and discontinuous in the site vicinity. Fringing the locality is a narrow strip of Columbus limestone, forming in places a 3 -ft surface stratum.

Underlying the glacial deposits of the area are several hundred feet of nearly horizontal beds of limestone, dolomite, and shale, through which preglacial streams carved a branched valley system. The distance from the soil surface to the bedrock on the Battelle property ranges from a few feet in areas along Big Darby Creek to over $200 \mathrm{ft}$ in the northwest corner of the property.

There are two aquifers in the Battelle site area. One is shallow and of minor im= portance and in underlain by the major aquifer of sand, gravel, and limestone. Yields up to 300 gal per min have been obtained from wells drilled into the principal aquifer in the area.

The ground water comes entirely from local precipitation and the shallow aquifer is recharged almost uniformly from the precipitation. The water table is everywhere less than 40 ft from the surface, and the contours are a subdued replica of the surface topography. Calculations indicate that water in the principal aquife in the vicinity of the Battelle site is moving at a rate somewhat less than 1 ft per day. The water in the till overlying the principal aquifer is estimated to flow at a considerably lower rate, measurable in hyndredths of a foot per day.

Ground-water movement downward through the thick till takes place very slowly. A long period of slow percolation occurs before water reaches a zone in which it may move laterally at appreciable rates. All the ground water is discharged into Big Darby Creek; hence, water entering the ground on the Battelle property is already near its place of discharge.

Big Darby Creek accounts for the principal surface-water flow. The mean flow is $420 \mathrm{ft}^{3}$ per sec, based on a 24-year record. Ground-water seepage from the impermeable deposits in Madison County adds little to stream flow. The water of Big Darby Creek is of good quality and is not polluted.

The conclusions of a report prepared by the U. S. Geological Survey on the geology and hydrology of the Battelle site are given in Appendix $C$. It is concluded that in case of liquid spillage, most of the liquid would flow overland to the Big Darby Creek and the remainder, once reaching the watex table, would also discharge into the creek. The changes for radioactive contamination of well water in the surrounding area areconsidered nil. 


\section{DESCRIPTION OF THE POWER REACTOR AND CRITICAL ASSEMBLY}

The Power Reactor

The Variable Moderator Reactor (VMR) system is a boiling light-water reactor which is controlled by varying the height of the moderator surrounding the fuel elements which changes the active core height. The reactor is fueled with slightly enriched $(\sim 2.2$ per cent) $\mathrm{UO}_{2}$ pellets in zirconium tubes about $0.5 \mathrm{in}$. in diameter. Thirty-seven fuel pins are arranged in a hexagonal array inside hexagonal cans which separate moderator water from coolant watex. The core is $6 \mathrm{ft}$ in diameter with a 6 -ft maximum core height. Operated at about $600 \mathrm{psig}$, this concept is applicable in power ranges from 20 to 200 electrical megawatts.

The core assembly is like a shell-and-tube heat exchanger, with the fuel-element cans representing the tubes and the vessel immediately surrounding the core representing the shell. This core assembly is contained in a second vessel with the region between vessels filled with water which serves as reflector. Steam condensate and makeup enter at the top of the moderator region (the region around the fuel cans) through a variable-speed feed-water pump. The pump, in combination with a control valve, maintains the proper water level in the moderator region by varying the rate of water addition. The moderator water passes downward through the core around the fuel elements and at the bottom passes into a coolant inlet plenum where it mixes with water from the reflector. The water then passes upward through the fuel elements and boils as it removes heat from the fuel pins. In an upper plenum the steam is separated from the water and drawn off while the water is recirculated downward through the reflector region to the coolant inlet plenum.

The Critical Assembly

As indicated previously, the purpose of the critical-assembly studies is to verify the assumptions and techniques used in formulating the digital computer code PURE'É. Consequently, the critical as sembly will not be a true model of the VMR power reactor. However, it will be a watermoderated assembly and by using special liquids with hydrogen densities lower than water, coolant-moderator-fuel distributions similar to those of the VMR can be simulated. Various combinations of fuel-element size and spacing, fuelpin spacing, and simulated coolant void fractions will be investigated. In the critical assembly there is no distinction made between moderator and reflector regions as is the case in the power reactor. Thus, any region not contained within a fuel element, the coolant region, is referred to as moderator region.

The critical assembly is build on an open framework on structural steel which supports the core above the floor and provides working platforms and supports for instrumentation and controls. Figure 5 shows this arrangement. The main features of the core, shown in Figure 6, include core tank, base plate, support structure, and fuel elements. The core tank is $7 \mathrm{ft}$ in $\mathrm{ID}$ and $7 \mathrm{ft}$ high. It is fastened to a 1 -in.-thick steel base plate $6-1 / 2$ ft above the floor. The I-beam frame supports the core assembly uniformly and transmits the load to the main vertical members of the reactor stand. 


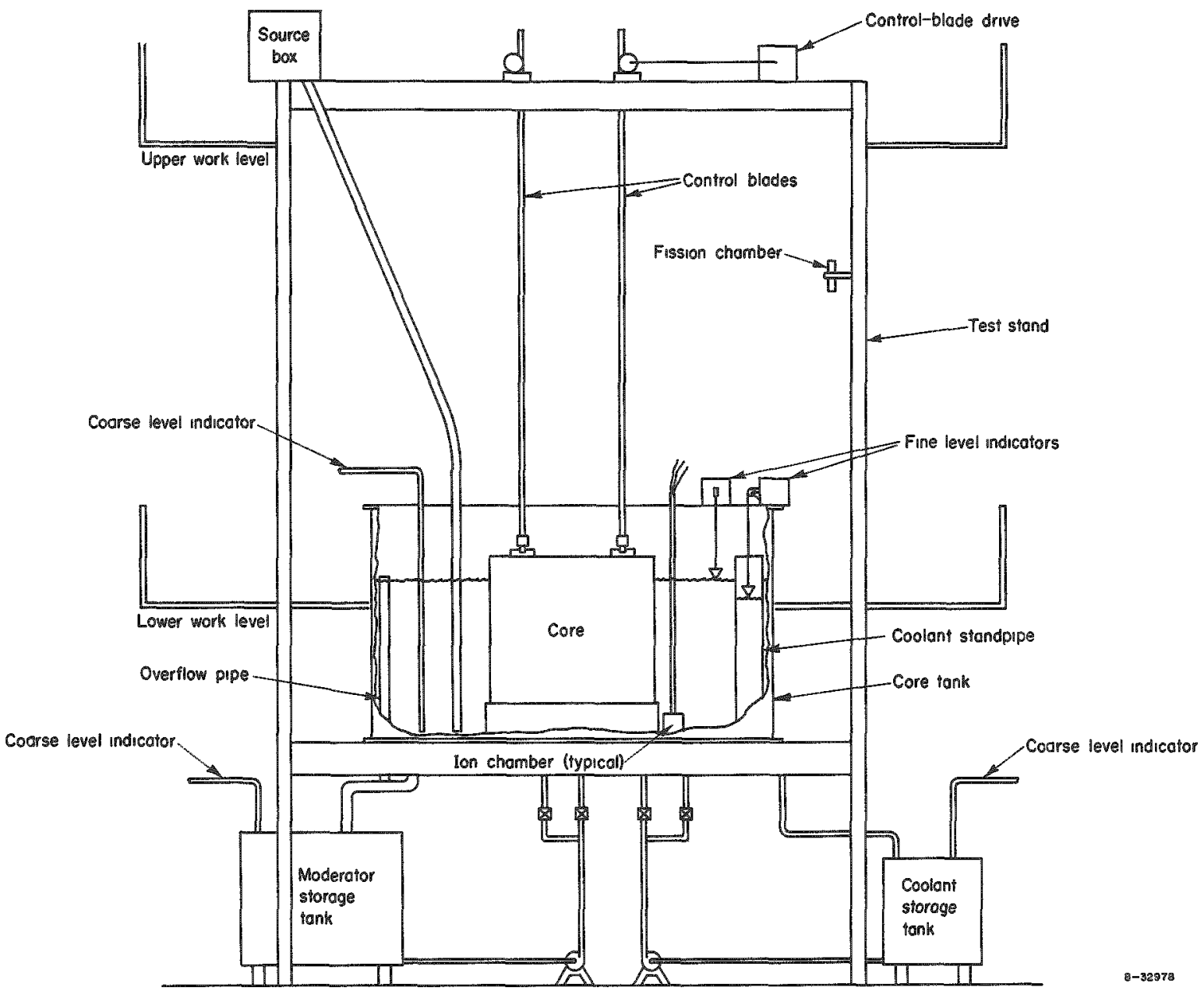

FIGURE 5. SCHEMATIC OF REACTOR ASSEMBLY 


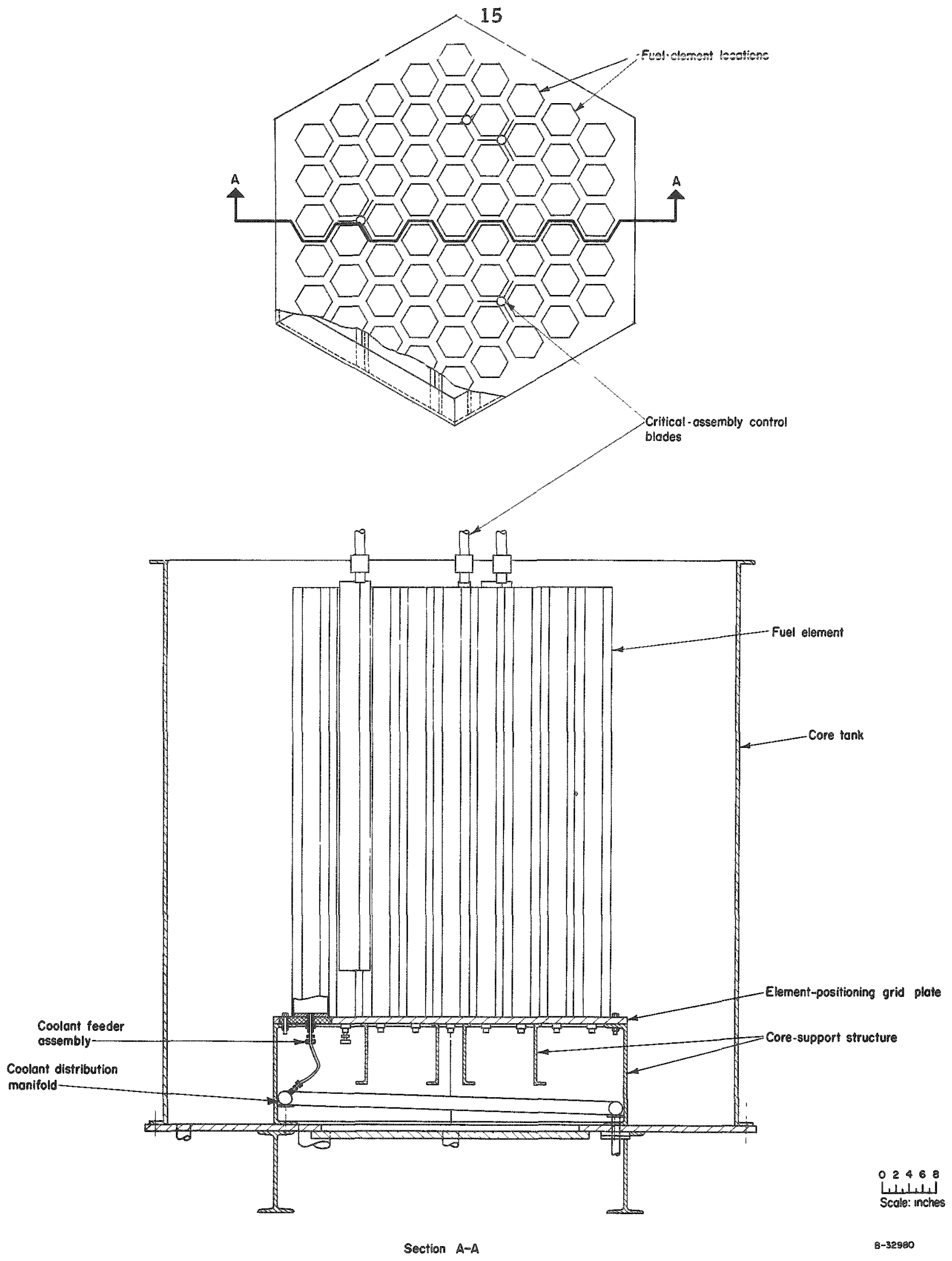

FIGURE 6. VMR REACTOR CORE AND SUPPORT STRUCTURE 
The core-support structure is a hexagonal framework made from 15 by $3 / 4-i n$. carbon steel channel stock with four modified channels (narrowed flanges) permanently fastened across this base. The element-positioning grid plate is fastened to the top of the hexagonal base, and is also hexagonal in shape. Holes through the element-positioning grid plate define the element lattice and provide a means for fastening the fuel elements in place. A different grid plate will be required for each fuel-element spacing. The four modified channels are positioned so they do not interfere with the holes in any of the grid plates.

A VMR critical-assembly fuel element is shown in Figure 7. The hexagonal can is 50-mil-thick stainless steel $62 \mathrm{in.}$ long. The threaded stud attached to the base of the element fits through a hole in the grid plate and the element is fastened securely to the grid plate with a nut. A manhole in the core-tank base plate (see Figure 6) gives access to the bottom of the element grid plate for this operation. The studs are bored axially to provide passage for the coolant-simulating liquids. A small positioning pin on each element base fixes the element orientation.

The fuel pins are sealed aluminum tubes approximately 0.5 in. in diameter and 62 in. long containing 1.8 per cent enriched $\mathrm{UO}_{2}$ pellets. The active fuel length is 46 in. The core contains about 2300 pins $\left(2500 \mathrm{~kg}\right.$ of $\left.U \mathrm{UO}_{2}\right)$. The pins stand on the base of the fuel can or element and are spaced at the top and near the bottom with aluminum positioning plates. These plates have holes drilled through them to allow the coolant liquid to fill the entire can. The upper positioning plate is designed to support all the pins so that they can be removed as a unit from the can. The entire fuel element including the can may be lifted by placing a bar in the lifting slot provided in each can. In this operation it is to be noted that the lifting slot supports only the weight of the can.

The liquid-handling systems are shown in Figure 8. The moderator-simulating liquid is light water. It is pumped into the moderator region through a pipe in the manhole cover of the base plate. Two pumping rates are provided by parallel, orificed legs in the fill-system. A 4 -in.-diameter dump line is provided for draining the moderator region rapidly. The dump and fill valves are remotely controlled, spring-to-open, airto-close type.

The coolant-simulating liquids will be furfural, furfuryl alcohol, and water. Appendix D discusses the use of furfural and furfuryl alcohol to simulate boiling void fractions. The coolant is pumped into a distribution manifold located within the hexagonal core-support structure. From there it flows through tubing and the hollow stud into each fuel element. Again, two pumping rates are available. A standpipe located in the core tank and connected with the coolant distribution manifold is provided for measuring the liquid height in the coolant region.

Coolant is drained from the fuel elements through the coolant dump valve into the top of the storage tank. Separate storage tanks are provided for furfuryl alcohol and furfural. A connection is provided between the moderator and coolant systems so the coolant region can be filled with water.

The main features of the critical assembly are summarized in Table 3. 


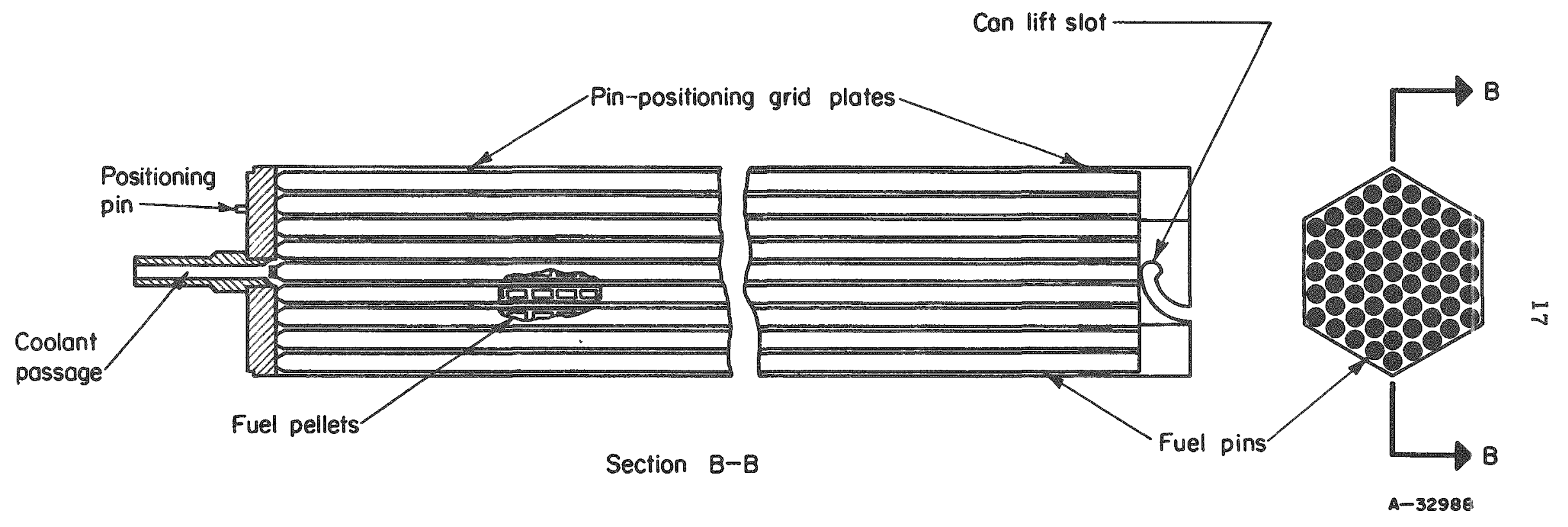

FIGURE 7. VMR FUEL-ELEMENT ASSEMBLY 


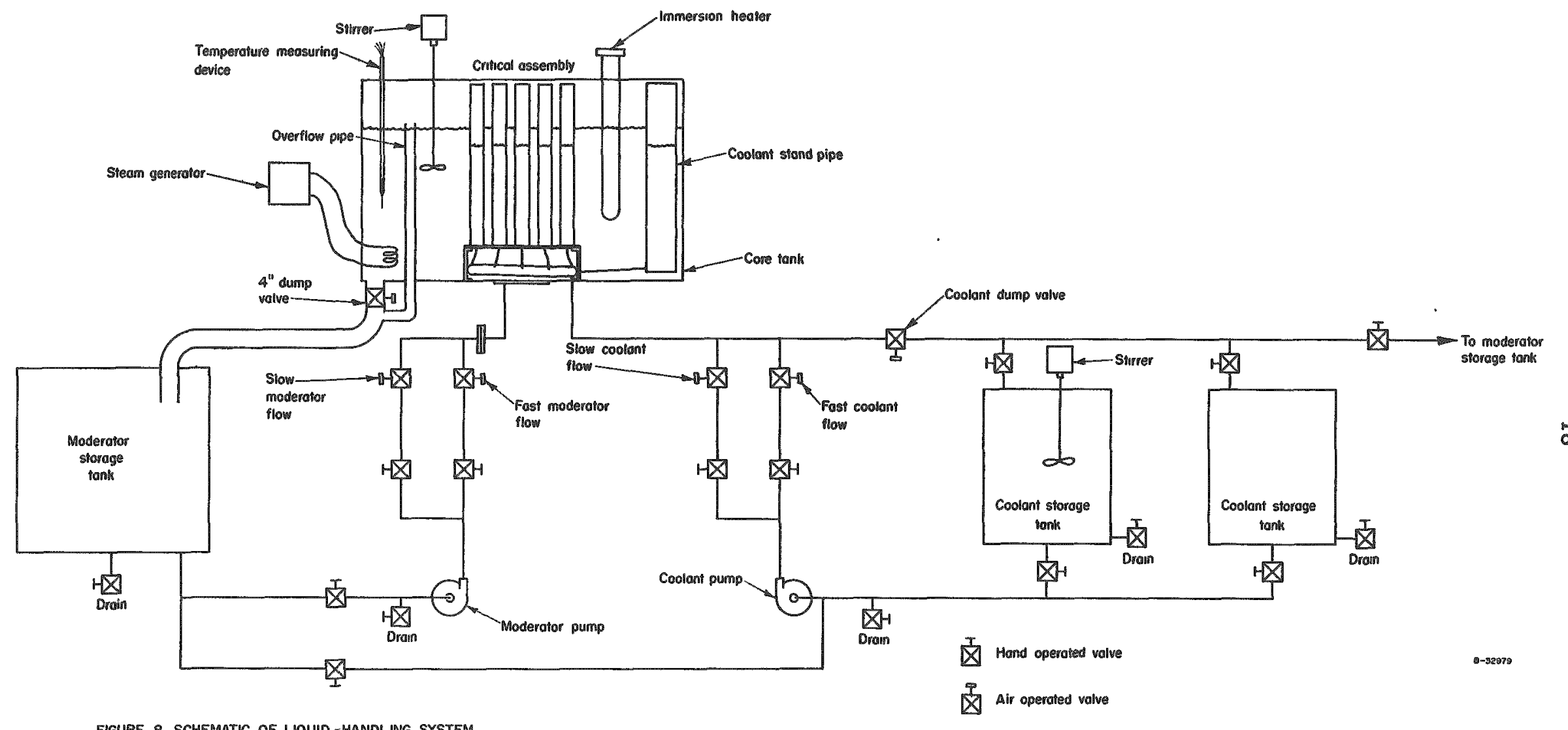

FIGURE \& SCHEMATIC OF LLQUID - HANDLING SYSTEM

FIGURE 8. SCHEMATIC OF LIOUID-HANDLING SYSTEM 
TABLE 3. CRTICAL-EXPERMENT DESIGN DATA

\section{Fuel Rod}

Fuel-pellet oD

Fuel-rod oD

Fuel-cladding thickness

Fuel active height

Total quantity of $\mathrm{UO}_{2}$

Fuel enrichment

Fuel-cladding material

\section{Core}

Coolant-simulating materials Moderator-simulating materials

Control-blade materials

Sarety blades

Number

Type

Size, each blade

Shim blade

Number

Type

Size

Fuel-element can

Material

Thickness

Shape

Element-grid plates

Material

Thickness

Number
$0.415 \mathrm{in}$.

$0.485 \mathrm{in}$.

$0.028 \mathrm{in}$.

46 in.

$2500 \mathrm{~kg}$

1. 8 per cent uranium-235

Aluminum

Water, furfuryl alcohol, furfural, air Water

Boral plate (aluminum and 35 per cent boron carbide, clad with aluminum)

3

$\Psi_{s}$ three-bladed

Approximarely $3-1 / 2$ by 48 in.

1

Flat, single-bladed

Approximately 2 by 48 in.

Stainless steel or aluminum

$0.050 \mathrm{in} .(0.100 \mathrm{in}$. if aluminum)

Hexagonal
Aluminum
1 in.
3 


\section{CONTROL AND SAFETY MECHANISMS}

The assembly has been designed to minimize the possibility of an accident resulting from malfunctioning equipment or from operator error. The principal features incorporated in the assembly to make it safe are described below.

\section{Control and Safety Blades}

Three $Y$-shaped safety blades and one I-shaped control blade will be used. They are constructed from 1/8-in. - thick aluminum-clad Boral. The $Y$-shaped blades have three equally spaced segments $3.5 \mathrm{in}$. wide and $48 \mathrm{in.}$ long. The I-blade is 2 in. wide and $48 \mathrm{in}$. long. Smaller, similarly shaped, sections of aluminum connect the blades to the drive assembly.

The details of a drive assembly are shown in Figure 9. The assembly consists of a motor-clutch unit, a Selsyn position indicator, a rack-and-pinion drive, and a hydraulic shock absorber.

The motor-clutch unit contains a reversible, a-c motor with a gear reducer, and a coupling clutch. The clutch is a stationary-field, electromagnetic type which operates on $90-v$ dc. It may be disengaged automatically or manually from the reactor control console by removing the power to the magnet.

Following the clutch is a unit containing the Selsyn position indicator and a pair of bevel gears. The Selsyn is coupled to the drive shaft through a pair of spur gears. It makes one revolution for 1 in. of control-blade travel. Furthermore, it is connected to the blade side of the clutch so that it indicates blade position rather than drive motor position. The indicating selsyn at the control console is connected to a revolution counter which is geared to read directly in inches.

The shaft from the Selsyn unit goes to the rack-and-pinion unit and drives the pinion gear. The rack is fastened to a round steel shaft which goes through the bearings in the rack-and-pinion housing. The control blade is connected to the lower end of this shaft. A hydraulic shock absorber is attached to the upper end. This consists of a piston fastened to the rod and a tapered cylinder filled with oil. This shock absorber strikes the upper face of the rack-and-pinion housing to arrest the motion of the steel shaft to which the control rod is attached.

The motor drives the blade upward or downward at approximately 20 in. per min. When the power is cut to the magnetic clutch, the control blade falls under the action of gravity with an acceleration of about 0.7 gravity to scram the reactor.

The rack-and-pinion unit is supported by a pair of 6-in. steel channels spanning the reactor assembly. The unit is clamped between the se channels by several bolts which pass through a flange in the rack-and-pinion housing and a clamp ring below the channel. The position of the support channel and the position of the rod between the channels can be varied over a considerable range. This permits complete freedom in the location of the control blades in the reactor core. 


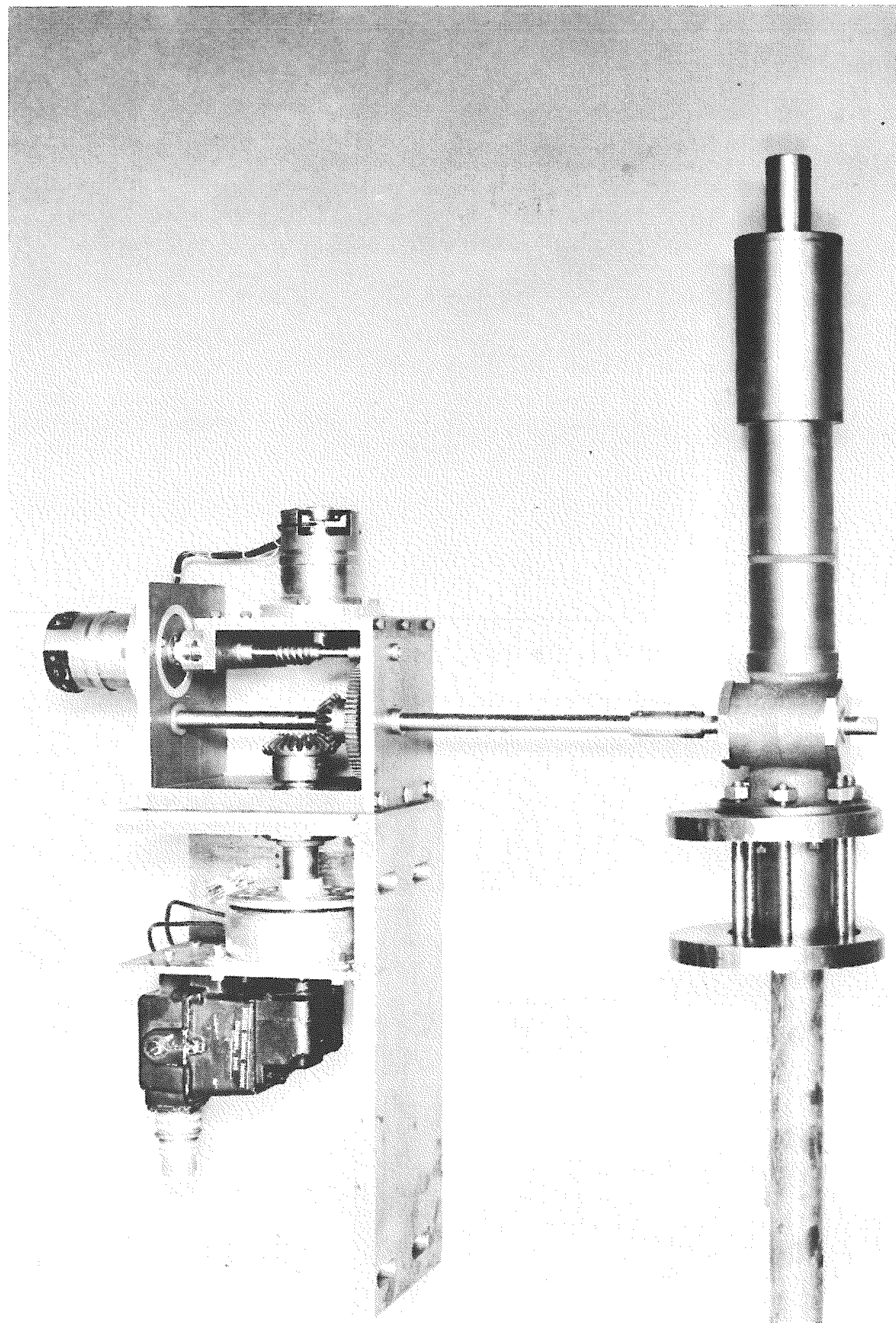

N3 1849

FIGURE 9. ROD-DRIVE UNIT 


\section{Startup Source}

A plutonium-beryllium neutron source will be used for reactor startup. The 5curie source when not in use is housed in a paraffin-filled box; it can be driven remotely into the reactor through a closed aluminum pipe which extends down into the tank alongside the core. The source will be positioned coplanar with the bottom of the fuel region. The source is moved by a flexible cable fastened to the source container. The cable drive mechanism is attached to the source box.

\section{Liquid-Level Control}

Fine control of the liquid level is provided by valves in the fill lines. These valves are controlled from the reactor console. When they are open the liquid leaks back through the pump impeller into the storage tank slowly so that fine control in lowering the liquids is possible.

The two pumping rates were selected to provide a reasonable filling time while maintaining a safe rate of reactivity addition. The maximum flow rates of the moderator and coolant liquids will be consistent with the limitation on maximum rate of change in reactivity, +0.04 per cent $\Delta \mathrm{k} / \mathrm{k}$ per sec. The minimum flow rates will be adjusted to about $30 \mathrm{gpm}$ for the moderator region and $5 \mathrm{gpm}$ for the coolant region. The se latter values are well below the maximum allowable rate presecribed for reactivity addition.

A positive secondary shutdown mechanism is provided by the 4 -in.-diameter dump valve in the moderator. This allows the core to be uncovered in approximately 2 min so that work on and about the core can begin in complete safety soon after shutdown.

The liquids levels will be measured by two methods. A rough measure to $\pm 1 / 8$ in. of the level in each storage tank and in the moderator and coolant region will be provided by Tank-o-Meters. This device measures the pressures required to bubble gas through a tube located in the liquids. A schematic of the Tank-o-Meter is shown in Figure 10. The length of the scale on the manometer depends upon the density of the manometer fluid. Since three coolants will be examined, interchangeable manometer scales will be used rather than compensating manometer liquids.

An accurate value of the liquid levels in the moderator and coolant regions will be obtained with an electrical surface-contact device. A schematic for this device is also shown in Figure 10. When a plumb bob, which is being driven downward, makes electrical contact with the liquid, the current through the liquid reduces the grid voltage of a 6 AG7 tube. The resulting plate current closes a relay which reverses the drive motor. When the surface contact is broken, the relay opens and the motor again reverses to drive the bob downward until contact is made. This oscillatory motion is transmitted by Selsyns to the control console. The amplitude of this oscillation is proportional to the resistivity of the liquid, but the surface contact breakage point has been observed to be essentially independent of the resistivity. The surface-contact breakage point is taken to be the liquid level and is repeatable to $\pm 0.005 \mathrm{in.}$ 


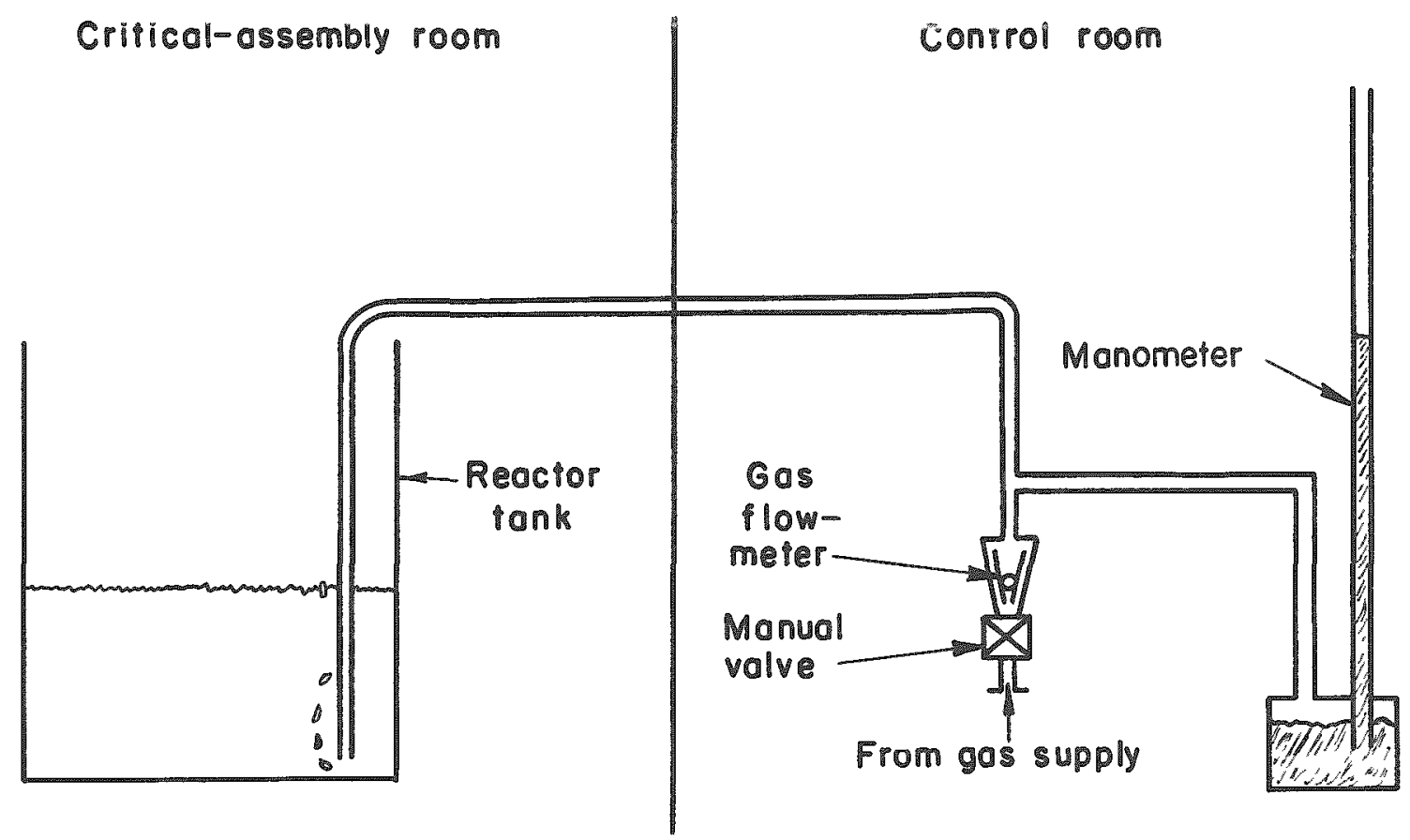

Schemotic of Tank-o-meter Indicator

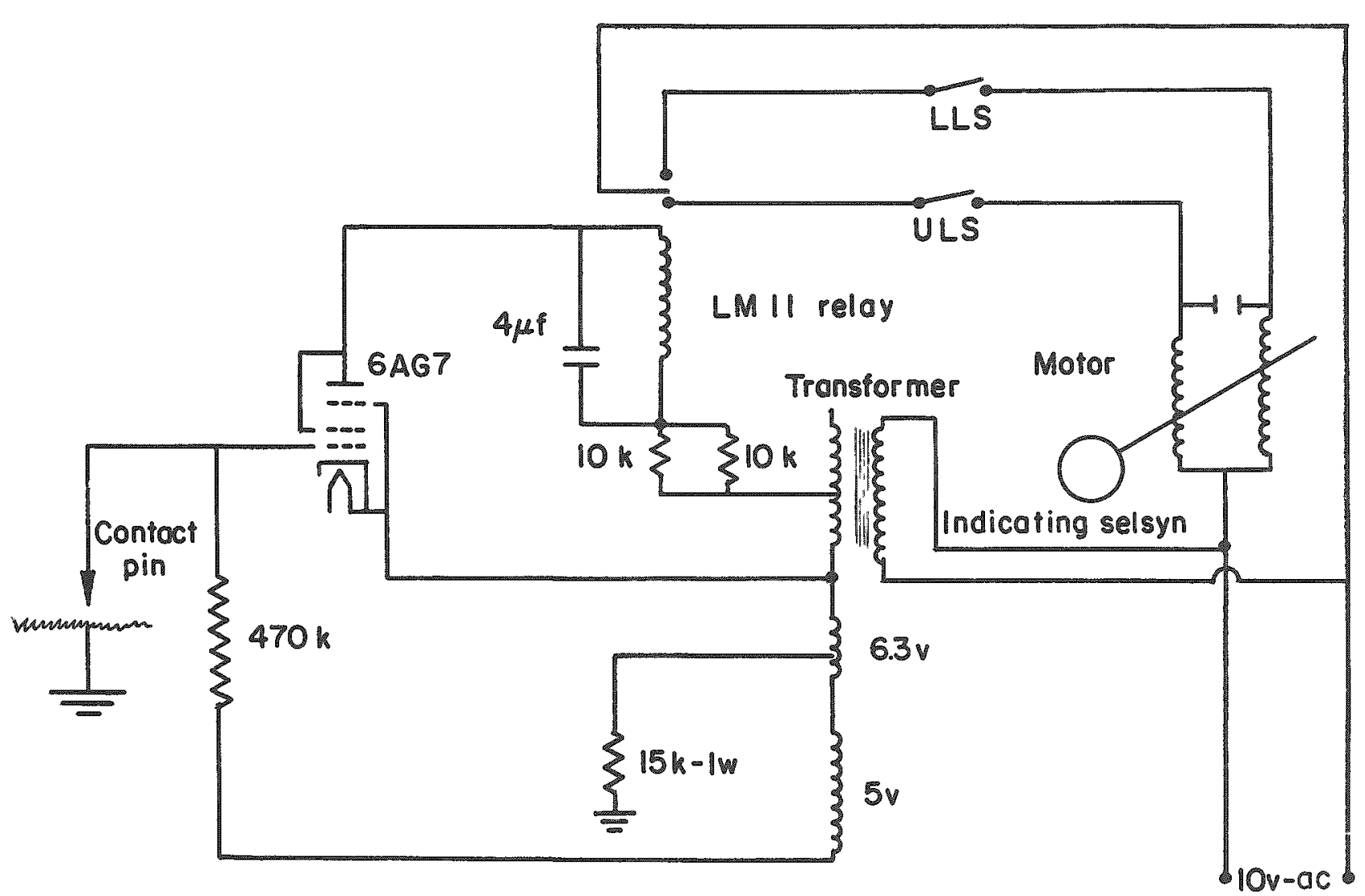

FIGURE 10. SCHEMATIC OF WATER-HEIGHT-MEASURING INSTRUMENTS 
Control and Research Instrumentation

The nuclear instrumentation is shown in the block diagram of Figure 11 . Three ion chambers are used as neutron detectors and monitors. These chambers are located around the core below the element grid-plate and away from the startup source. One chamber is connected to a linear vibrating-reed-type electrometer on the console. Negative feedback to the input lowers the input impedance and permits the use of a long cable. The output of this instrument is connected to a strip-chart recorder for visual indication of neutron flux. This output is also monitored by a meter scram relay for the safety circuit.

The other ion chambers are connected to logarithmic electrometers. The output from these electrometers is connected directly to the safety circuits and to differentiating circuits. The differentiated logarithmic signal provides visual period indications and activates the period scram circuits. The output from one of the se logarithmic electrometers is also connected to a strip-chartrecorder to provide a record of the log of the power or flux level. The slope of the curve on this chart will be a record of the reactor period.

A gamma-radiation monitoring channel consisting of a high-voltage supply and a scintillation detector gives a visual indication of the power level. This channel is also connected into the safety circuits. The detector will be located approximately 20 ft. from the core to prevent overloading at operating power levels.

In addition to the safety or control circuits, two research circuits are provided. These channels provide accurate low-level information for startup and accurate neutron indications at operating levels when required. They are also used to provide an aural indication of power level and to provide additional visual indication of power level. One circuit consists of a fission-chamber, a linear amplifier, and a scaler with provisions for a digital recorder. The fission chamber and preamplifier are located in the assembly room. The other channel uses a boron trifluoride counter as detector. It consists of a linear amplifier, scaler, and high-voltage supply. The counter and its preamplifiers are located in the assembly room. Both of the se channels are pulse-counting instruments and are independent of the safety instrumentation.

\section{Safety and Interlocking System}

Each of the control devices just discussed is interconnected in a manner that prescribes the operational procedures and provides automatic shutdown in case of an error or malfunction. A block diagram of the safety and interlock system is given in Figure 12. This system allows only the following sequence of events in the operation of the critical facility. With the control console switched on, reactor room doors closed, and instrument scram circuit reset, the operator can close the moderator dump valve and insert the startup source. Power is automatically supplied to the control-blade-drive clutches. After the source is positioned in the reactor, power is available for driving the control blades one at a time. When the two safety blades are completely withdrawn either the moderator or coolant liquid can be pumped into the core. The maximum moderator pumping rate is well below the capacity of the open dump valve. Thus, if the dump valve has not been closed at this point the moderator a rea does not fill. When, as a result of pumping the liquids, the neutron flux reaches a set value, great enough to be detected on 


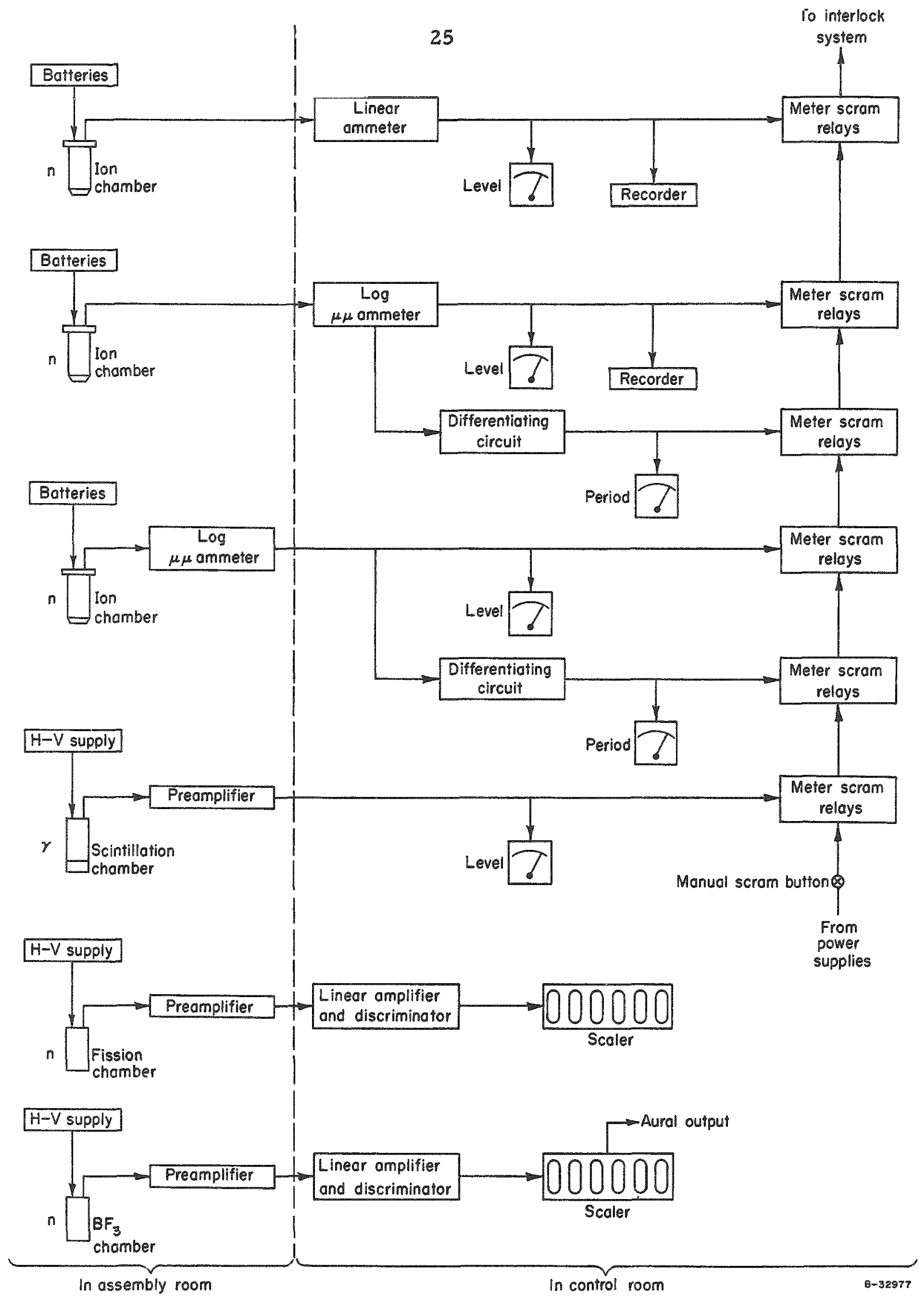




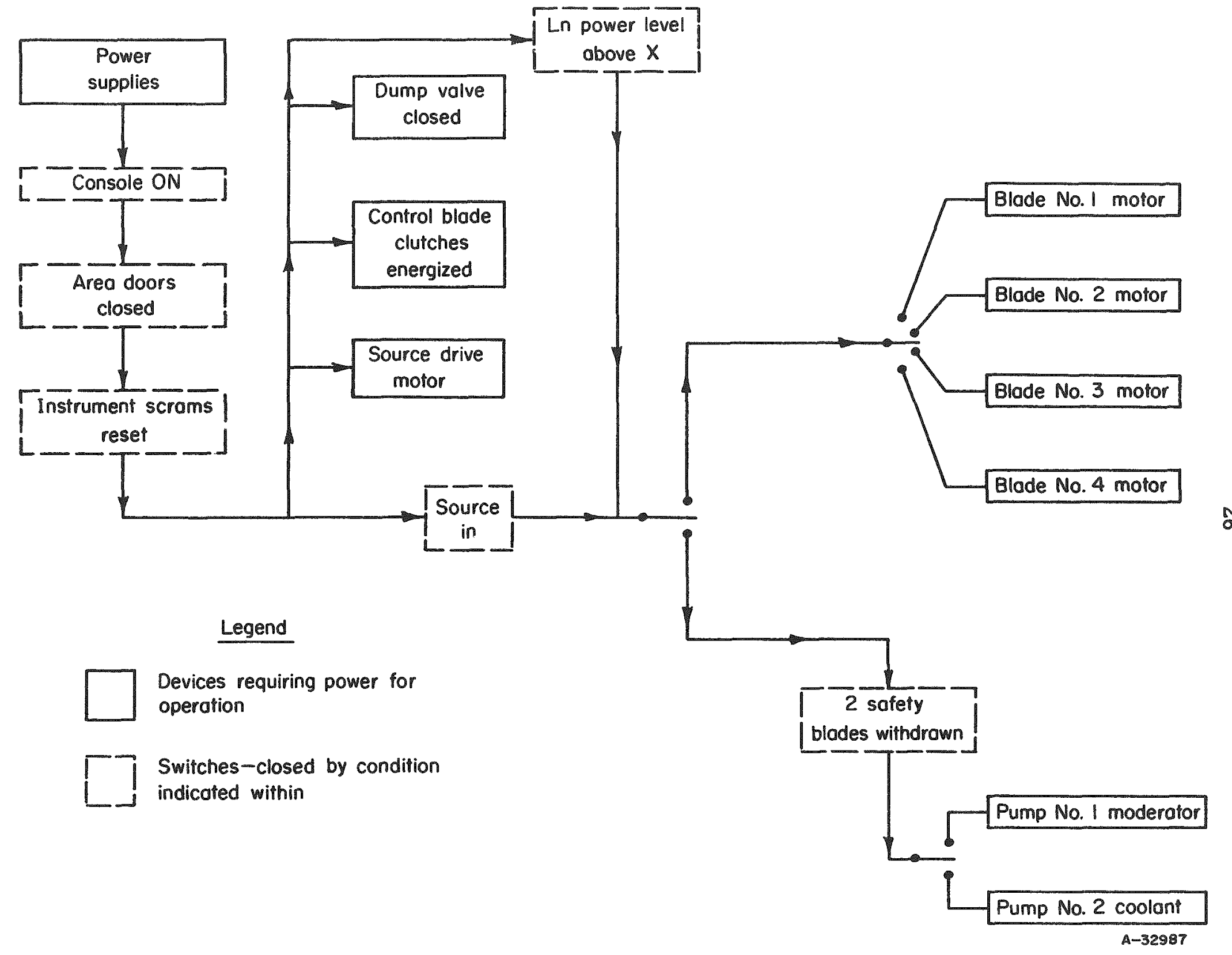

FIGURE 12. BLOCK DIAGRAM OF SAFETY AND INTERLOCK SYSTEM 
the instrument apart from the source, the source interlock function is transferred automatically to a power-level recorder. I'hus, the operator may withdraw the startup source and still drive the control blades or pump liquids. If at any time after the source has been withdrawn the neutron level falls below this set level, the operator must reinsert the source before the control blades or pumps can be actuated.

The interlocking is accomplished with microswitches and relays which must be. actuated to allow operation. The malfunction of one of the se switches, or the devices which they monitor, will not allow the conditions of the interlock system to be met and, therefore, further operation will be impossible.

A scram is initiated if the power level or reactor period exceeds the values set in the instrument scram circuits. In this event the power is interrupted to the dump valve, control rods, and pumping systems and all valves open and the rods drop into the core, shutting down the reactor. In a similar manner, failure of a power supply or opening the door into the reactor area will initiate a scram. Of course, a manual scram button is available which triggers the same sequence of events.

\section{SPECIAL CHARACTERISTICS OF THE VMR-CA}

Characteristics relative to the operation and safety of the VMR-CA have been estimated for a typical critical-assembly configuration. Although some of the se characteristic may vary somewhat from core to core the variations are not significant in determining the shutdown mechanism for the maximum credible accident. The core chosen as typical is one with intermediate spacing of fuel elements and pins. Parameters for this core are listed in Table 4.

\section{Criticality of a Typical Core}

In estimating the critical height of the typical core, the critical equation was written

as

$$
k_{\mathrm{eff}}=\frac{\eta \in \mathrm{pf}}{1+\mathrm{M}^{2} \mathrm{~B}^{2}}=1.0
$$

where

$\eta$ was calculated for 1.8 per cent fuel enrichment assuming $\eta(235)=2.06$ which gave $\eta=1.693$.

$\epsilon$, the fast-fission factor, was assumed to be a function of water-to-uranium ratio only. This as sumption has been checked experimentally for closepacked fuel-pin lattices.(1) The value obtained from this reference for a wate - to-uranium ratio of 2.25 is $\epsilon^{28}=1.036$. The contribution by uranium-235 was similarly evaluated using data from Volpe, et al.(2) The result was $\epsilon^{25}=1.048$. These values for $\epsilon^{28}$ and $\epsilon^{25}$ resulted in an over-all fast-fission effect of $\epsilon=1.086$.

(1) See References at end of text. 
TARLE 4. PARAMETERS OF TYPICAL CORE

\begin{tabular}{|c|c|c|}
\hline & Element pitch & $5.95 \mathrm{in.}$ \\
\hline & Fuel-pin pitch & $0.633 \mathrm{in}$ \\
\hline & Ratio of coolant volume to $\mathrm{UO}_{2}$ volume & 1.20 \\
\hline & Ratio of moderator volume to $\mathrm{UO}_{2}$ volume & 1.05 \\
\hline & Coolant void fraction & 0 \\
\hline & Fuel-pin diameter & $0.485 \mathrm{in}$. \\
\hline & Fuel diameter & $0.415 \mathrm{in}$. \\
\hline & Fuel-element length & 48 in. \\
\hline & Fuel & $\begin{array}{l}\mathrm{UO}_{2}, 1.8 \text { per cent enriched } \\
\text { density }=10.4 \mathrm{~g} \text { per } \mathrm{cm}^{3}\end{array}$ \\
\hline. & Fuel tube & Aluminum 0.028 in. thick \\
\hline & Fuel-element shroud & $\begin{array}{l}\text { Hexagonal, stainless steel } \\
\text { can } 4.94 \text { in. across flats, } \\
0.050 \text { in. thick }\end{array}$ \\
\hline & Core radius & $47.6 \mathrm{~cm}$ \\
\hline
\end{tabular}


p, the resonance escape probability, was developed from the equation

$$
p=\exp \left[-\frac{N_{U} V_{U}}{\xi \Sigma_{S} V_{H_{2} O}} 11.5(1+1.92 \mathrm{~S} / \mathrm{M})\right]
$$

where

$$
\begin{aligned}
& N_{U} \text { - number of uranium atoms } \\
& V_{U} \quad \text { - volume of uranium } \\
& V_{H_{2} O} \text { - water volume } \\
& \xi \quad \text { - logarithmic energy loss per collision } \\
& \Sigma_{S} \quad \text { - scattering cross section of moderator } \\
& S / M \quad \text { - surface-to-mass ratio of uranium oxide fuel pins. }
\end{aligned}
$$

Results given by this equation agree to about \pm 1 per cent with measured values for full density $\left(10.6 \mathrm{~g}\right.$ per $\left.\mathrm{cm}^{3}\right) \mathrm{UO}_{2}$ rods with $a .0 .387-\mathrm{in}$. radius. (2) For the VMR critical-assembly lattice the calculated value is $\mathrm{p}=0.851$.

f, the thermal utilization, was calculated by diffusion theory. First, the ratio of fuel absorptions to total absorptions in the coolant region was evaluated for a uniform themal-flux distribution, i.e., disadvantage factor of unity. The result was $f_{0}=0.915$. Next, the coolant and moderator regions were treated as a cylindrical tworegion problem. The calculated cell disadvantage factor for this case was $f_{1}=0.845$. The the rmal vitization is the product $f_{0} f_{1}$ or $f=0.774$.

$M^{2}$, the migration area, is the sum of the age, $\tau$, and thermal-diffusion area, $I^{2}$. The age was calculated from

$$
\tau=\tau_{\text {water }}\left(\frac{\text { cell volume }}{\text { water volume + uranium volume }}\right)^{2}=58.5 \mathrm{~cm}^{2} \text {. }
$$

The diffusion area, $L^{2}$, was evaluated from

$$
L^{2}=L_{\text {water }}^{2}(1-I)=1.9 \mathrm{~cm}^{2}
$$

These combine to give

$$
M^{2}=\tau+L^{2}=60.4 \mathrm{~cm}^{2} \text {. }
$$

Using the itemized values above and. a core radius of $53 \mathrm{~cm}$ (including radialreflector savings) the calculated critical height of the reactor is $76 \mathrm{~cm}$ (about $2.5 \mathrm{ft}$ ). This value includes an axial-reflector savings of $6.5 \mathrm{~cm}$. The multiplication factor, $k_{\infty}=1.21$. 


\section{Reactivity Coefficients}

Reactivity coefficients pertinent to the safety of the critical assembly were calculated. The results are given in Table 5.

The average void coefficient of reactivity was estimated by calculating $k_{\text {eff }}$ for the typical core with reduced water density and a constant core height. A value was obtained for no void and for 15 per cent voids in the core.

The fuel-temperature coefficient of reactivity due to Doppler effect was obtained assuming that

$$
\frac{1}{I_{\text {eff }}} \frac{d I_{\text {eff }}}{d T}=1.0 \times 10^{-4} / \mathrm{C},[\text { see Reference }(3)]
$$

where $I_{\text {eff }}$ is the effective resonance integral for uranium-238. The Doppler effect for uranium-235 in this enrichment range is negligibly small compared to that for uranium238. (4) The fuel-temperature coefficient due to linear expansion of the fuel as it is heated was calculated assuming the resultant change in multiplication was due only to a change in the rmal utilization.

The change in reactivity due to an increase in core height, $\mathrm{H}$, was computed from

$$
\frac{1}{k} \frac{\partial k}{\partial H}=\frac{2 \pi^{2} M^{2}}{k_{\infty} H^{3}}
$$

If a uniform voiding of the core resulted in a height increase, the reactivity contribution of this effect would be $\frac{1 / k \frac{\partial k}{\partial H}}{A_{c}}$, were $A_{c}$ is the cross-sectional area of the core. This

results in a positive contribution to the void coefficient of about $4 \times 10^{-7}$ per $\mathrm{cm}^{3}$ for this case. The negative contribution caused by the actual formation of voids is much larger as can be seen in Table 5 .

\section{PLAN OF NORMAL OPERATION}

The general administrative control and operating responsibility for the Critical Assembly Facility are outlined in the organization chart of Figure 13. The critical assembly operating rules and general laboratory rules are included in Appendix $\mathbf{E}$. These rules are quite general so that they apply not only to VMR research but to all other critical assembly studies which Battelle has conducted. Special limitations which will apply to VMR studies are given below. Following these, operations which are required to perform the necessary experiments will be discussed. 
TABLE 5. SPECIAL CHARACTERISTICS OF TYPICAL VMR CRITCAL-ASSEMBLY CORE

\begin{tabular}{|c|c|c|}
\hline Characteristic & Symbol & Value \\
\hline Infinite multiplication factor & $k_{\infty}$ & 1.21 \\
\hline $\begin{array}{l}\text { Neurrons produced per neutron } \\
\text { absorbed in fuel }\end{array}$ & $\eta$ & 1.693 \\
\hline Fast-fission factor & $\epsilon$ & 1.086 \\
\hline Resonance escape probability & $\mathrm{p}$ & 0.851 \\
\hline Thermal utilization & $f$ & 0.775 \\
\hline $\begin{array}{l}\text { Average void coefficient at } \\
\text { constant height }\end{array}$ & $\left.\frac{\partial \mathrm{k}}{\partial \mathrm{v}}\right)$ & $\begin{array}{l}-0.80 \times 10^{-5} \text { per } \mathrm{cm}^{3} \\
\text { (zero void) } \\
-4.2 \times 10^{-5} \text { per } \mathrm{cm}^{3} \\
\text { (15 per cent void) }\end{array}$ \\
\hline Average Doppler coefficient & $\left.\frac{\partial k}{\partial T}\right)_{D}$ & $-1.61 \times 10^{-5}$ per $c$ \\
\hline $\begin{array}{l}\text { Average fuel -expansion } \\
\text { coefficient }\end{array}$ & & $-2.3 \times 10^{-6}$ per $c$ \\
\hline $\begin{array}{l}\text { Reactivity coefficient of } \\
\text { Water height }\end{array}$ & $\frac{1}{k} \frac{\partial k}{\partial H}$ & $\begin{array}{l}1.75 \times 10^{-3} \text { per cm } \\
\text { (for } 2.5-1 \text { - } 2 . \text { high } \\
\text { core) }\end{array}$ \\
\hline Prompt-neutron lifetime & & $5.0 \div 10^{-4} \mathrm{sec}$ \\
\hline $\begin{array}{l}\text { Estimated worth of one control } \\
\text { blade }\end{array}$ & $\frac{\Delta k}{k}$ & -1. 1 per cent \\
\hline
\end{tabular}




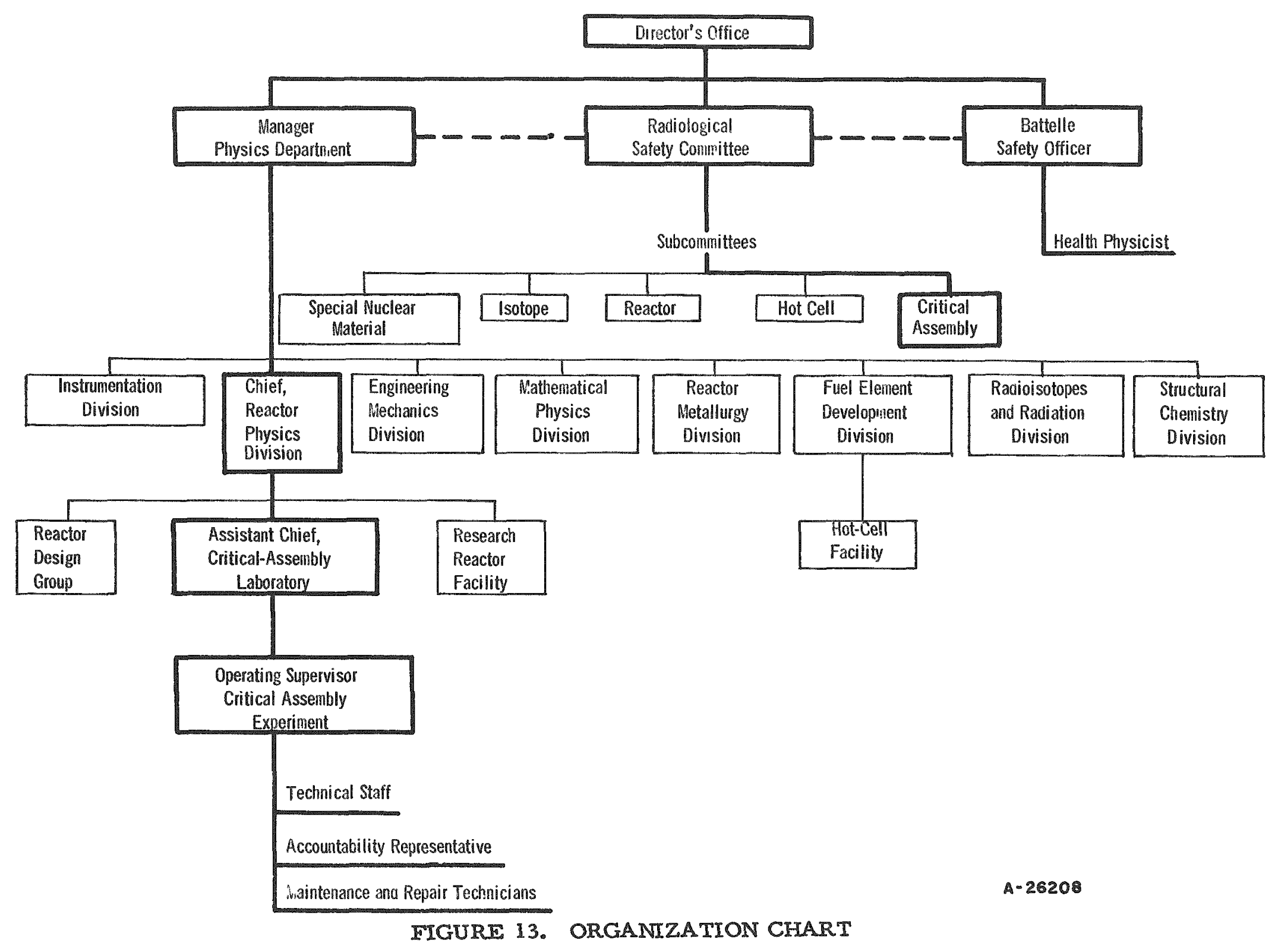


General Limitations on Experiments

\section{Control Limitations}

A basic limitation on all experiments and operations will be a maximum rate of change of reactivity of 0.04 per cent $\Delta \mathrm{k} / \mathrm{k}$ per sec. This limitation will apply to all controls which may be operated remotely. This includes control blades and coolant and moderating liquids when the reactor $\mathbf{k}_{\text {eff }}$ is greater than about 0.95 .

The reactor will not be taken critical with less than 2 per cent $\Delta \mathrm{k} / \mathrm{k}$ available for quick shutdown. This limitation can be satisfied by interlocking so that two control blades must be withdrawn from the core and poised above the fuel region before the startup procedure can continue. A third control blade will be moved upward in an iterative manner so as to be always immediately above the liquid level. If released, this rod could initiate shutdown before the others because of its proximity to the active core region.

Power Limitations

The VMR critical assembly will normally be operated in the power range from $1 \mathrm{mw}$ to $1 \mathrm{w}$. For activation experiments the core may be operated at 20 to $40 \mathrm{w}$ for short periods of time.

The power-level scrams are normally preset at 0.1 to $1 \mathrm{w}$ depending on the requirements of the particular experiment. In experiments where foils or wires are activated, the power-level scrams will be set at 50 to $100 \mathrm{w}$. In all cases the period trips will be set to scram the reactor if the period is less than $4 \mathrm{sec}$. The period trips are set at the same value regardless of the experiment.

\section{Limitations on Core-Assembly Operations}

Assembly operations are considered a part of the normal operations since it is anticipated that several different core configurations will be required during the course of the experiment. Procedures and controls will be adopted to guard against criticality hazards during the construction. The procedures to be used during construction are described in detail in Supplement No. 5 to Procedures Manual BMI-PM-607. Only general features of the procedures are outlined here.

(1) The amount of uranium -235 handled at any one time will be limited to the quantity contained in one fuel element.

(2) The location of the uranium and the amount assembled at any one point will be carefully controlled by having a flow and balance record at each point where material is handled.

(3) A supervisor will be appointed who will have responsibility for each fuel-handling operation.

In addition to these precautions, the multiplication of the reactor will be measured, recorded, and evaluated during assembly of the core. Since assembly will be carried out 
with all liquids completely drained from the reactor tank the multiplication is expected to be very small.

Precritical Operation Checkout

Prior to each day's reactor operation, and more often if the supervisor deems it necessary, a complete check will be made of the instrumentation and safety mechanisms of the reactor. Each radiation detector will be checked with a neutron source. Each scram circuit will be checked and each scram mechanism will be operated using a source to initiate the scram. The interlocks will be checked by attempting operating contrary to the design procedure. Following this, a visual check will be made of the facility and the room, the door to the assembly room will be closed, and the checkout form will be signed by the person making the check.

Experiments and Procedures

Material in this section discusses general studies which will be performed with this critical assembly. The experiments are not listed in any specific order since the order will depend on the need for particular information and on scheduling which will attempt to minimize the time for the over-all program.

Criticality Studies

Critical liquid heights will be measured for about 15 combinations of fuel-element size and spacing, fuel-pin spacing, and coolant liquid density. The number of fuel elements in the reactor will be 37 except for a special test in which 61 fuel elements may be used. Each fuel element will contain 61 fuel pins in the 37 element cores. If a 61 -fuelelement core is investigated the number of fuel pins per element will be reduced to 37 so that the total fuel inventory (about $40 \mathrm{~kg}$ of uranium-235) will be the same.

In the critical configuration the core will have a full radial reflector but only a lower axial reflector. The moderator and coolant liquid levels after being adjusted to be the same at the critical condition will be read from the liquid-level indicators.

Each approach to criticality will follow a set procedure which is described below and which, to a large extent, is enforced by the interlock systern. The initial approach, which is described first, will be used the first time the reactor is made critical and on any other occasion when significant changes have been made in the reactor or in its instrumentation. Once the critical state of a given reactor configuration has been determined subsequent approaches to criticality will be made with less data taking and plotting.

Initial Approach to Criticality. The initial approach to critical will be made with 37 fuel elements in the core. This core is not expected to be critical with full water height in the moderator region and total void in the coolant region; nor is this core expected to be critical with full water height in the coolant region and void in the moderator region. However, both cases will be investigated to gain more information about the reactor characteristics. Since the case with full water height in the moderator region and void in the coolant region appears to be the least reactive, it will be investigated first. 
To insure safe operation, these experiments will be conducted as if the core might go critical as the water hoight is increascu.

After the necessary steps in the interlock system have been satisfied, water will be pumped into the moderator region until the level reaches the bottom of the fuel. The I-shaped or fine control blade (see Figure 6) will be moved upward as the liquid level is raised. With the moderator level at the bottom of the fuel, count rates and meter readings from the neutron-sensitive chambers will be read and plotted. After examining the se data, the liquid level will be raised about 3 in. and another neutronmultiplication check made. This procedure will continue until the water level reaches the top of the fuel or the system is critical. If the system is critical it will be apparent by noting the constant or slowly increasing neutron level after the source has been removed from the core. The magnitude of each increase in water height will be based on data from the previous point. The results will be available in graphical form prior to each subsequent step.

For a number of liquid heights, multiplication checks will be made with the $Y-$ shaped (or coarse) control blade fully in and out of the active core region. The difference in multiplication between the two cases can be used as a reliable guide to the worth of this blade in the critical condition.

After reaching full water height or criticality the moderator water will be dumped into the moderator storage tank so the next experiment can begin.

The entire procedure outlined above will be repeated with water being pumped into the coolant region only.

As mentioned previously, neither of the se systems is expected to be critical at full water height. The critical condition will be achieved with water in both moderator and coolant regions, aided by previous experiments. In this experiment water will be pumped into the coolant region to the level of the bottom of the fuel. After a multiplication check, moderator water will be pumped to the same level. Coolant and moderator levels will be raised, one liquid at a time with the magnitude of each increment based on multiplication data. This proces s will continue in stepwise fashion with continuous indication of neutron multiplication. At each liquid height, the multiplication with the $Y$ control blade fully in and out will be assessed in order to have an estimate of its worth. After criticality is attained, final adjustments will be made so that the liquid levels are equal when the reactor is just critical.

This stepwise approach to the critical condition will be used after any significant change to the core.

Subsequent Approaches to Criticality. Once the critical condition for a particular core has been determined, a simpler means of going critical will be employed for subsequent operation of the same reactor geometry. Based on experimental findings the pumping rate will be adjusted, if necessary, so that reactivity is not added at a rate faster than 0.04 per cent $\Delta \mathrm{k} / \mathrm{k}$ per sec above a $\mathrm{k}_{\mathrm{eff}} \approx 0.95$. Changes in liquid level and rod position will be made continuously rather than stepwise. At several liquid heights neutron multiplication will be checked to insure that the progress toward critical is as expected. In addition, the operator is trained to observe all neutron-level and period indications. One pulse counter monitoring the power level provides an aural signal during the approach to the critical condition. 
Instrumentation which must be in operation and other critical-as sembly operation rules which apply during the se times are listed in Appendix $E$.

Reactivity-Coefficient Measurements. The reactivity effect of changes in liquid level, temperature, and hydrogen density will be measured. Other experiments may be performed to evaluate the reactivity effect of material modifications to the core or to local regions of the core.

Reactivity worth of gross changes in coolant and moderator level will be measured by comparing the position of calibrated rod before and after the change. The worth of incremental changes in liquid level will be evaluated by period technique. In the period technique the reactor will be placed on a positive period by a small change in liquid level. The measured stable period can be related to the reactivity effect of the change in liquid level.

To measure temperature coefficient of reactivity, the core will be made critical at a given temperature; a control rod will then be inserted a small distance to make the reactor slightly subcritical. After moving the neutron source into the subcritical core, the heating system and stirring motors will be turned on to raise the temperature uniformly across the core. The behavior of the temperature in the reactor will be observed on the several temperature indicators and the reactivity behavior of the reactor will be noted by the multiplication changes in the subcritical core. After a temperature rise of 3 to $10 \mathrm{C}$ has occurred, the heat will be turned off, with the exception of low-capacity immersion heaters, and the core allowed to come to equilibrium. The source will be withdrawn and the control rod adjusted to again make the reactor critical. If the temperature coefficient is small or strongly negative and if the temperature rise is slow and uniform, subsequent temperature measurements may be carried out with the reactor at or near critical at all times.

Voids in the coolant will be simulated by using liquids with different hydrogen densities in the coolant region. As part of the research the reactivity effect of voids will be estimated. To determine the reactivity effect of voids with a constant reactor geometry, subcritical multiplication measurements may be required since a given configuration may be subcritical at some hydrogen densities of interest. In subcritical multiplication measurements, the source-jerk technique or direct measure of reciprocal neutron level will be employed.

\section{Activation Measurements}

Axial and radial flux distributions will be determined by activating indium, manganese, or uranium foils and wires at various points in the core. Cadmium differences will be taken to separate the the rmal from the epicadmium activities. The foils will be mounted in the liquid region in specially constructed plastic holders. Other foils will be mounted on or within the fuel pins and other structural components of the reactor. About 60 of the 2300 fuel pins will be a split-design to accept foils for activation studies.

Optimization of Design

Experiments may be conducted to aid in optimizing the reactor design. For example, special formed polyethylene blocks may be used to simulate the nonuniform void 
condition in a boiling water reactor. It may be that nonuniform fuel element of fuel pin spacings may be investrgated in partal or tull core loading. No experiments are planned at other than atmospheric conditions or under conditions which significantly alter the hazards associated with operating this critical assembly.

Processing and Disposal of Radioactive Materials and Solutions

The only special nuclear material which will be processed at the Critical-Assembly Laboratory is a number of small uranium foils for power measurements. If other proces sing is required, it will be done in the uranium area at the main Battelle Laboratories.

The liquids used in the experiments - water, furfural, and furfuryl alcohol - will not contain sufficient contaminants to cause them to become radioactive at the flus level of the critical assembly. However, these liquids will be checked regularly on a routine basis and will be checked specially prior to disposal. Because of the low power operation, radioactivity in fuel and structural materials will not be a problem. Air sampling and smear tests are taken routinely in the vault and assembly areas as an extra precaution against fission-product contamination. Materials containing fission products are handled on blotting paper with gloves. If contaminated, the paper is sealed in marked containers in the storage vault. When the containers are filled they are processed at Battelle's Hot Cell Laboratory along with other similar contaminated materials.

\section{HAZARDS CONSIDERATIONS}

A critical assembly, like all nuclear reactors, is a source of radioactivity produced directly in the fission process or indirectly from the radioactive materials made therein. However, because of its low-power operation, the critical assembly, unlike power or test reactors, does not accumulate significant amounts of radioactivity in normal operation. Consequently, the hazards associated with its operation are direct radiation from the core during a power excursion or the release of fission products produced during the transient. Thus, the results of an incident involving a critical assembly would be considerably less severe than those from an incident with a power reactor.

On the other hand, an accident with a critical assembly, although unlikely, is, because of the experimental aspects, sonewhat nore probable than with a routinely operating reactor. To compensate for this increased probability a number of precautionary measures can be taken. For example, experiments can be designed so that minimum excess reactivity is available when the core is critical. Also, the facility can be operated with special instrumentation and operational rules so as to minimize equipment failure or operator error.

In analyzing the present assembly, hazards from radiation produced by the assem bly during normal operation were considered. The analysis shows that the exposure received by the operating staff is much less than the maximum permis Direct irradiation of public persons is not a problem.

Incidents which might lead to power excursions have also been considered and are discussed in the following sections. Problems attendant to the handling of furfural and furfuryl alcohol are discussed in Appendiz D. 
Hazards During Normal Operation

Hazards during normal operation of the VMR critical assembly include: (1) direct radiation through the assembly-room walls and sky shine around and over the walls, (2) radiation exposure in handling irradiated fuel elements, and (3) possibily inhalation of airborne fission products.

Direct Radiation

Fuel loadings (uranium-235) in the VMR critical assembly will be comparable to loadings in past experiments and, consequently, operational neutron and gamma fluxes are expected to be about the same magnitude.

The neutron flux in the control room based on past experience will be approximately 10 thermal $\mathrm{n} /\left(\mathrm{cm}^{2}\right)(\mathrm{sec})(\mathrm{w})$ and 20 epithermal $\mathrm{n} /\left(\mathrm{cm}^{2}\right)(\mathrm{sec})(\mathrm{w})$. The epithermal neutrons appear to arise largely from sky shine and because of multiple scattering have energies close to thermal energy. This fact has been verified by measurements with a Hurst dosimeter, which measures approximately tissue equivalent fast-neutron flux. After calibration with a polonium-beryllium neutron source, the instrument was placed in the control room during a power run at about $20 \mathrm{~m}$ reactor power; no reading was recorded.

Measurements with a survey meter and film badges indicate that the gamma dose rate is such that for $40 \mathrm{wmhr}$ of operation, personnel receive only 0.03 of maximum permissible exposure.

Handling Irradiated Fuel

In the course of the experiments there will be a number of occasions when irradiated fuel pins will be removed from the core and disassembled. In particular, measurements of thermal utilization, resonance escape probability, and fast-fission effect require fuel handling. While elements are being handled the immediate area is continually monitored for gamma-radiation level and ring monitors (gamma-ray sensitive films) and film badges are worn by personnel handling fuel pins.

However, the most important safeguard during these times is administrative control of operations. A senior physicist is present whenever fuel is handled. All personnel engaged in the operations are well acquainted with the appropriate instruments and precautions to be applied.

Fission-Product Hazard

Gaseous fission products are not expected to represent a hazard since all fuel is encapsulated within aluminum tubes. There may be minor exceptions to this where special tests may require flux-or power-distribution measurements within individual pins. These exceptions will be rare and the quantity of fuel is so small $(\sim 10 \mathrm{~g})$ and the irradiation so slight $\left(\sim 10^{-5} \mathrm{w}-\mathrm{hr}\right.$ per $\left.\mathrm{g}\right)$ that no airborne fis sion-product hazards are expected. 
Acridental Reactivity Additiona

Procedures and instrumentation used in these studies have been designed to predict the beginning of any hazardous condition permitting the operator to take corrective action. Operator error or equipment failure is protected against by having a number of parallel safety mechanisms. It is, nevertheless, possible to postulate cases where a combination of serious equipment failures and/or operator error could produce a hazardous situation. Since the probability or credibility of a particular occurrence is difficult to evaluate, a number of hazards have been studied and are included below. The one which adds the greatest reactivity is deemed the maximum accident. Its consequences are followed in a separate section of this report.

Continuous Addition of Reactivity

The rate of addition of reactivity by pumping liquids or withdrawing control rods will be adjusted so that the maximum change is 0.04 per cent per sec. As shown in Appendix $F$, the level and period scrams are preset to initiate shutdown before reactivity added at this rate can have serious consequences. Thus, to be hazardous this incident would require failure of all safety circuits.

Accidental Flooding of the Coolant Region

Generally, the coolant region is filled to a level equal to that of the moderator. In a few experiments, the coolant region will be completely voided so that addition of liquid in the coolant region would add reactivity to the system.

The reactor multiplication has been calculated to be $k_{\text {eff }} \approx 0.78$ without liquid in the coolant region. Flooding an individual fuel element is estimated to increase $k_{e f f}$ to 0.80 so the reactor is still subcritical. It is true that the fuel cans are interconnected through 3/8-in. fill lines and a common manifold (see Figure 8). However, the interconnection is through such a tortuous path that common flooding instantaneously is not considered a possible accident. Similarly, the incredibility of several or many cans rupturing simultaneously precludes this case from consideration.

An accident may be postulated in which the coolant manifold piping fractures with the moderator region completely filled. Two alternate paths will be open for the moderator to drain (again note the piping diagram of Figure 8). The resistance encountered in draining into the coolant region is many times that for draining into the moderator storage tank. It is to be noted that the coolant dump valve and valve leading to the moderator tank will be open for these studies.

\section{Dropping an Object Into the Critical Reactor}

In some experiments the core will be critical with less than full moderator height and a large increase in liquid level would add significant amounts of reactivity; (1/k) $(\partial \mathrm{k} / \partial \mathrm{H})$ has been estimated to be 0.04 per cent per $\mathrm{cm}$ to 0.35 per cent per $\mathrm{cm}$ depending on the reactor height. A sizable object dropped into the core tank would add reactivity proportional to its displacement. In the most pessimistic case the object could pass into the reflector region directly without contacting the fuel-element shrouds to break the fall. 
The cross-sectional area of such an object is limited to about $1 \mathrm{ft}^{2}$; something life an electrician's or mechanic's tool chest might satisfy the se requirements. A $4 \mathrm{ft}^{3}$ object dropped endwise into the reflector with the reactor critical at 2 -ft active core height (i.e., maximum reactivity worth for adding moderator) would add 1.5 per cent reactivity.

\section{Coolant Mixing Problem}

Since the coolant must be selected by manual control of valves, it is possible to pump water in place of furfural, etc. If undetected this would cause gross inaccuracies in the data. However, the rate of liquid addition is adjusted to accommodate the most reactive of the liquids so no power excursion would be produced.

\section{ACCIDENT ANALYSIS}

\section{Maximum Accident}

The maximum "credible" accident appears to be an object falling into the reflector region increasing the effective core height. For the minimum critical core height, $2 \mathrm{ft}$, the reactivity coefficient for changes in height is $3.5 \times 10^{-3}$ per $\mathrm{cm}$. This value was obtained from the calculated value for the typical core assuming the coefficient varies as $1 / H^{3}$ [see Equation (7)]. The maximum water displaced by an object which can be dropped directly into the reflector is $4 \mathrm{ft}^{3}$ which would raise the water height $4.3 \mathrm{~cm}$ for the minimum moderator volume, $113 \mathrm{ft}^{3}$. The reactivity addition would be about 1.5 per cent added rapidly enough to be considered a step increase.

Because of low thermal conductivity in the fuel, a large air gap between fuel and cladding $(7 \mathrm{mils})$, and short-time duration of the excursion ( $\sim \mathrm{sec})$, essentially no heat is lost from the fuel during the transient. The shutdown mechanisms are Doppler effect, thermal expansion of the fuel, radiolytic-gas formation, and, finally, boiling water.

Of the four mechanisms, the first two are prompt, i.e., they are instantaneously effective. The third mechanism is slower, the minimum delay time being the time required to generate enough hydrogen to reach the solubility limit of hydrogen in water. The results of Spert I experiments $(5)$ indicate that radiolytic-gas formation is an important shutdown mechanism and that the time for gas formation is probably less than the time of the power burst. The fourth mechanism requires a long time (relative to the time of the transient) before it becomes significant and, therefore, has been neglected.

Energy coefficients of reactivity were obtained from temperature, void, and height coefficients of reactivity listed in Table 5 and the following parametric values and assumptions.

(1) The specific heat of $\mathrm{UO}_{2}$ is $0.064 \mathrm{cal} /(\mathrm{g})(\mathrm{C})$

(2) The mass of $\mathrm{UO}_{2}$ in the 2 -ft-high reactor core is $1.25 \times 10^{6} \mathrm{~g}$

(3) One molecule of hydrogen is produced per $100 \mathrm{ev}$ absorbed in the water 
(4) Six Mev per fis sion or about 3.25 per cent of the fission energy is absorbed in the water.

The calculated energy coefficients of reactivity are:

$$
\begin{aligned}
& \left(\frac{1}{k} \frac{\partial k}{\partial F}\right)_{\text {fuel temperature }}=-5.5 \times 10^{-5} \text { per megawatt-sec } \\
& \left(\frac{1}{k} \frac{\partial k}{\partial F}\right)_{\text {radiolytic gas }}=-5.5 \times 10^{-4} \text { per megawatt-sec. }
\end{aligned}
$$

The latter number is a net effect including the positive contribution of increasing water height.

Assuming the radiolytic gas is formed at the center of the core and expels the cylindrical watex volume above the midplane as a piston, the following equations describe the transient:

$$
\begin{aligned}
& P=\frac{M g}{A}+\frac{M}{A} \frac{d^{2} X}{d t^{2}}+P_{0}, \\
& P A X=N R T, \\
& \frac{d N}{d t}=c P, \\
& \frac{d p}{d t}=\frac{k p}{l}, \\
& k \quad=k \int_{0}=a A-b \int_{0}^{t} p d t,
\end{aligned}
$$

where
$A=$ cross-sectional area of core
2 = void coefficient of reactivity
$b=$ power coefficient of reactivity due to metal heating
$c=$ gas-formation rate, moles per megawatt-sec
$g$ = gravitational constant
$k$ = reactivity above prompt critical
$M=$ mass of water accelerated
$N$ = moles of gas formed
$P=$ gas pressure
$p=$ reactor power 


$$
\begin{aligned}
& P_{0}=\text { atmospheric pressure } \\
& R=\text { gas constant } \\
& T=\text { gas temperature, } K \\
& X=\text { height of gas laye }, i . e ., \text { "piston" travel } \\
& \ell=\text { prompt-neutron lifetime. }
\end{aligned}
$$

A solution of the coupled equations [(8) through (12)] would require the use of a digital or analogue computer. The limitations on the physical model postulated do not warrant this. For this reason, upper and lower limits on the excursion were evaluated by investigating two similar but simpler models.

To solve for the upper limit on the excursion energy, only the Doppler temperature effect was used as a shutdown mechanism, i.e., no radiolytic-gas production. The equations for this case are:

$$
\begin{array}{r}
\frac{d p}{d t}=\frac{k p}{l}, \\
k=k-b \int_{0}^{t} p d t .
\end{array}
$$

These equations have the solution(6)

$$
p(t)=q \operatorname{sech}^{2}\left[\sqrt{\frac{b q}{2}}(t-\alpha)\right]
$$

where

$$
\begin{aligned}
& q=p_{i}+\frac{\left(k_{0}\right)^{2}}{2 b l}, \\
& p_{i}=q \operatorname{sech}^{2}\left[\sqrt{\frac{b q}{2}} \alpha\right], \\
& p_{i}=\text { initial power. }
\end{aligned}
$$

The total energy is

$$
E \approx \frac{2 k_{0}}{b},
$$

and the time to peak power is given by

$$
\alpha \approx \frac{\ell}{k_{\mathrm{o}}} \ln \left(\frac{2 \mathrm{k}_{\mathrm{o}}^{2}}{\ell \mathrm{b} \mathrm{p}_{\mathrm{i}}}\right) .
$$

To estimate the lower limit on excursion energy radiolytic-gas formation was included and the equations become

$$
\frac{\mathrm{dp}}{\mathrm{dt}}=\frac{\mathrm{kp}}{\ell}
$$




$$
k=k_{0}-68 b-(b+d) \int_{c_{0}}^{t} p d t
$$

The total energy for this case is

$$
E=\frac{2\left(k_{0}-68 b\right)}{b+d}+136
$$

These equations as sume that the radiolytic gas formation becomes a shutdown mechanism only after a time, to, during which there is 68 megawatt-sec energy release. This energy release supplied the radiolytic gas required for equilibrium solubility in the coolant and moderator liquids.

In both cases

$$
\begin{aligned}
b= & \text { energy coefficient of reactivity due to fuel heating }=-5.5 \times 10^{-5} \\
& \text { per megawatt-sec } \\
\mathrm{d}= & \text { energy coefficient of reactivity due to void formation }=-5.5 \times 10^{-4} \\
& \text { per megawattonec. }
\end{aligned}
$$

The energy generated in an excursion for the two limiting cases is presented in Figure 14. For the maximum accident, a 1.5 per cent $\Delta \mathrm{k} / \mathrm{k}$ step increase, the energy release is between 160 and 310 megawatt-sec.

\section{Core- Temperature Considerations}

In both the upper-and lower-limit analyses, the average fuel temperature, $\overline{\mathrm{T}}_{f}$, at the end of the excursion can be estimated by assuming all the heat is stored in the fuel pins. This gives

$$
\bar{T}_{f}=E / M_{u} C_{p}=\mathbb{E} / 0.335
$$

where

$$
\begin{aligned}
& M_{\mathrm{u}}=\text { mass of fuel in active core } \\
& \mathbf{C}_{\mathrm{p}}=\text { pecific heat of uranium dioxide, and } \\
& \mathrm{E}=\text { the total excursion energy in megawatt-sec. }
\end{aligned}
$$

The maximum fuel temperature will be approximately 2.5 times this value.

Figure 15 shows the averaged fuel temperature with the melting-point temperature of aluminum indicated. If no radiolytic gas were formed, the aluminum cladding could melt at points where it contacted the fuel 10.007 in. gap on the average). The maximum fuel temperature is shown in Figure 16. In the region of maximum temperature (core center) little or no melting of $\mathrm{UO}_{2}$ is predicted for even the most pessimistic shutdown mechanism. Melting of aluminum is probable in the region of maximum fuel temperature. 


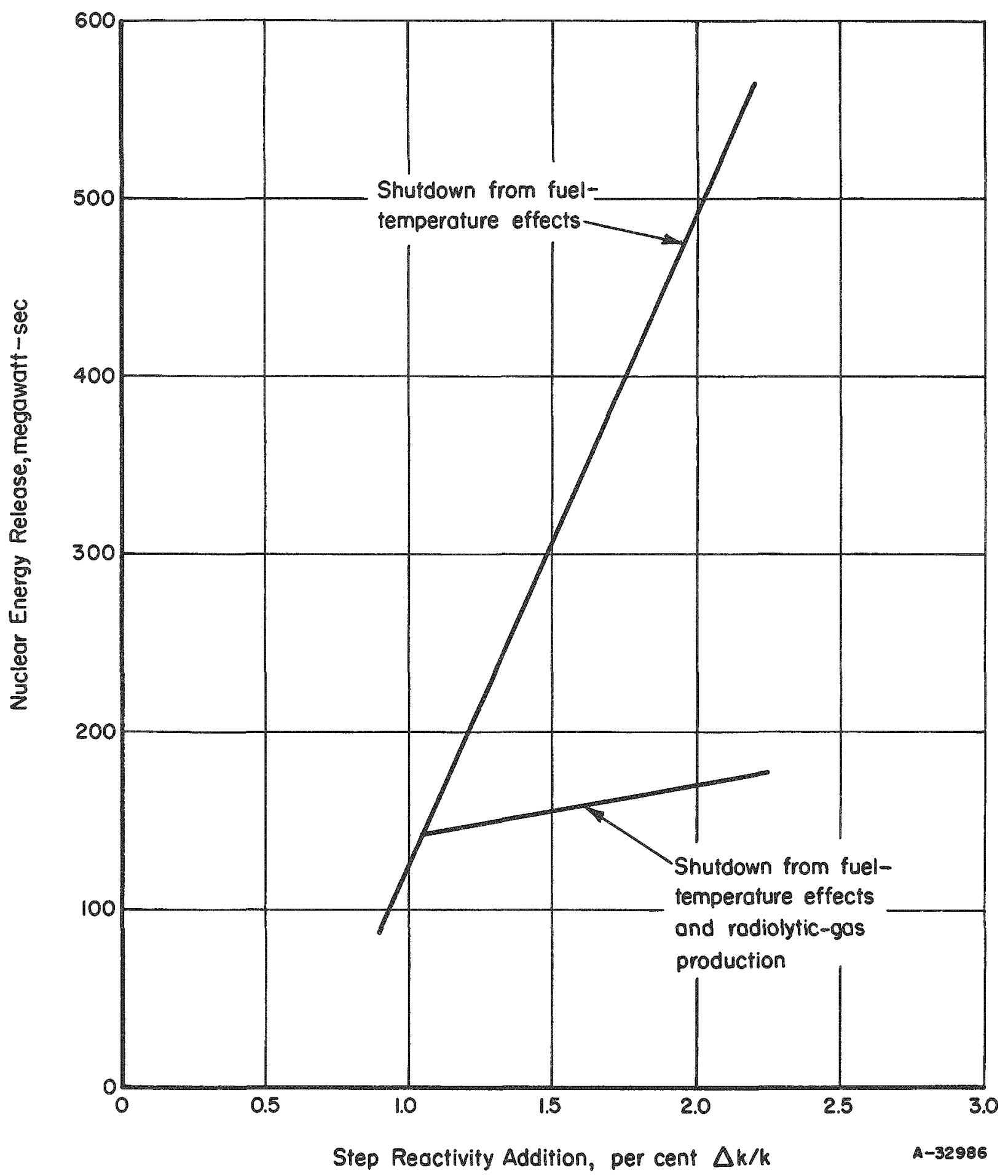

FIGURE 14. NUGIEAR-ENERGY RELEASE 


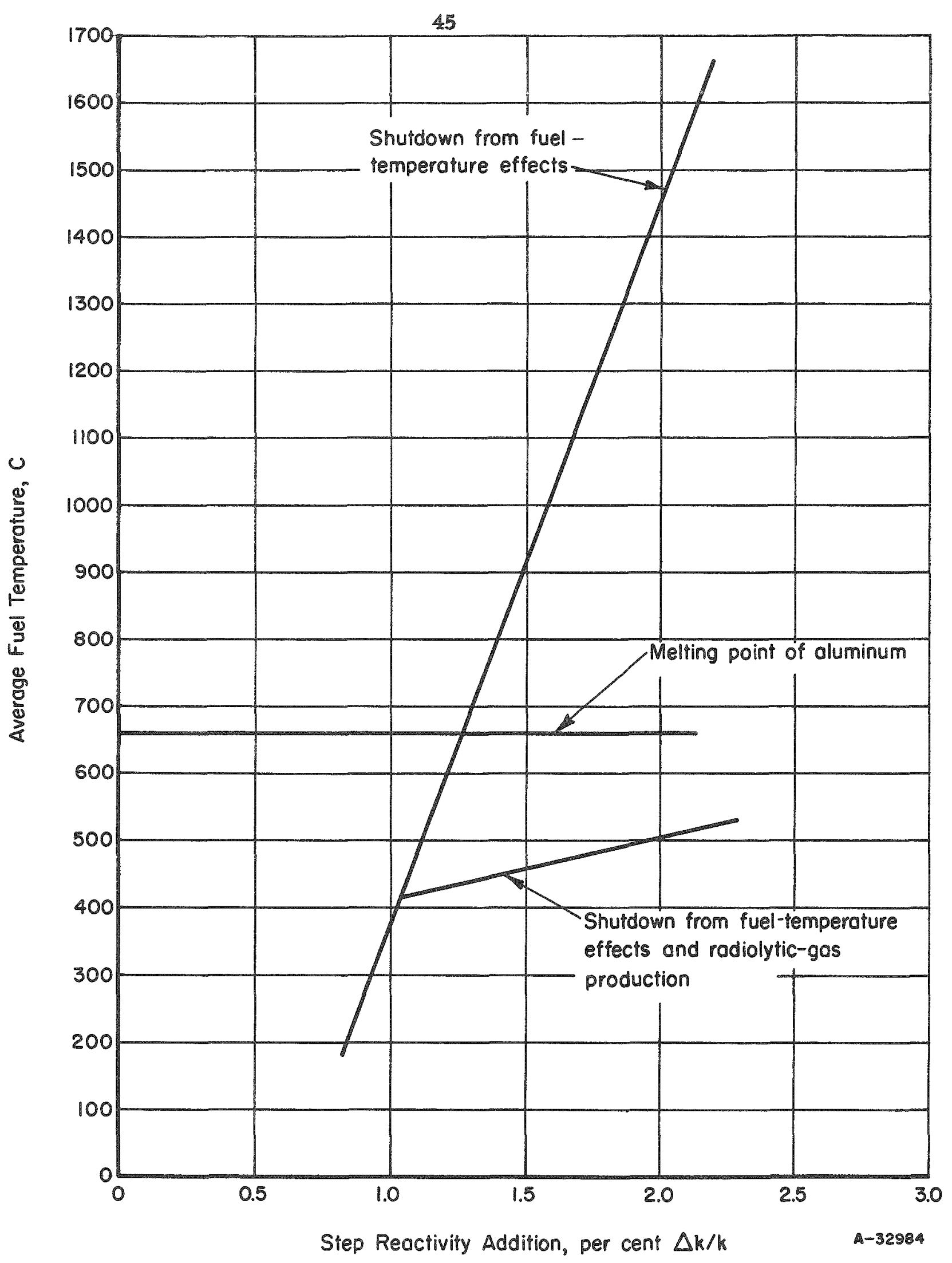

FIGURE 15. CORE-AVERAGE UO TEMPERATURE FOLLOWING A STEP REACTIVITY INSERTION 


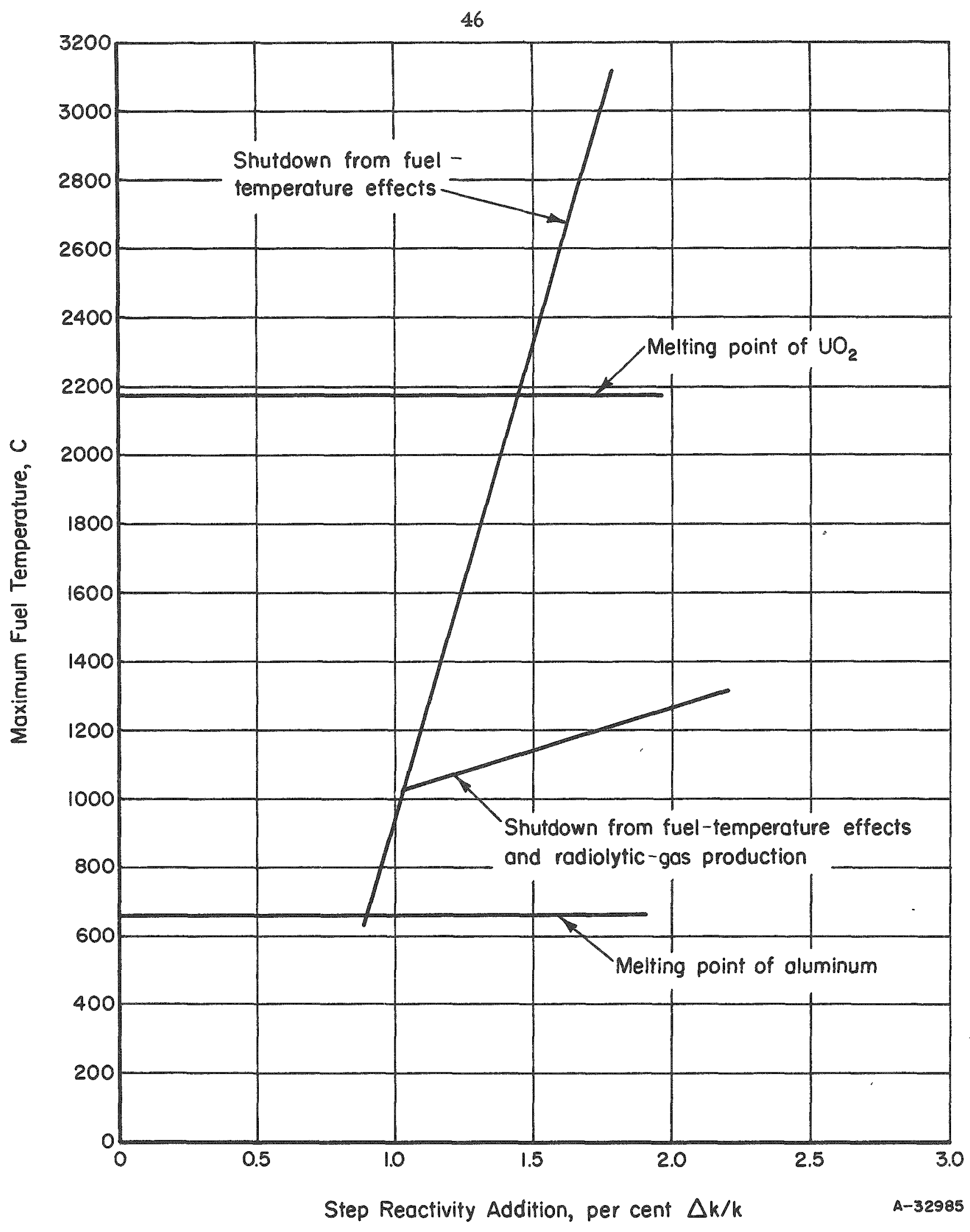

FIGURE 16. MAXIMUM UO TEMPERATURE FOLLOWING A STEP REACTIVITY INSERTION 
In the 2 -ft-high active core, the re is $3400 \mathrm{~g}$ of aluminum. Assuming half of this melts and reacts completely with water, the energy release from the reaction would be about 52 megawatt-sec. This release is based on a heat of formation of $\mathrm{Al}_{2} \mathrm{O}_{3}$ of $400 \mathrm{kcal}$ per $g$ formula weight, or $7400 \mathrm{cal}$ per $\mathrm{g}$ of aluminum. This additional chemical-energy release would come after the power peak of the nuclear excursion and, hence, would not contribute appreciably to shutdown.

\section{Discussion and Results of the Accident}

The as sumption of no heat transfer from the fuel during the accident seems justified by the results of the analysis. The total time required for the burst is about 1 sec, and an estimate of the heat transferred across the 7 mil air gap in this time interval indicates only about 7 megawatt-sec is lost from the fuel. The limits of nuclear-energy release from this accident are 160 to $310 \mathrm{megawatt-sec.} \mathrm{The} \mathrm{larger} \mathrm{value} \mathrm{causes} \mathrm{no} \mathrm{ap-}$ preciable melting of fuel and no vaporization of fuel. Some aluminum may melt and result in a chemical-energy release from the aluminum-water reaction. This chemical energy would be expected to contribute to the ultimate shutdown of the reactor but not to the initial termination of the burst.

Since none of the fuel is vaporized, and probably none melted, no fission-product activity would escape from the buildings. Hence, there is believed to be no hazard to the public persons. If all aluminum melted, some 4 to 5 pex cent of the gaseous fission products might escape into the critical-assembly room, based on experiments conducted at Battelle on fission-product release from UO $\mathrm{UO}_{2}$. The air activity in the room would then be $10^{4}$ to $10^{5}$ times weekly tolerance immediately after the accident. The normal dilution factor for controlled release of radioactive gases within Battelle's exclusion limit is of the order of $10^{-4}$ to $10^{-5}$ so that this accumulated single-burden activity can be safely exhausted.

\section{REFERENCES}

(1) Klein, D., et al., "Measurements of $f, p, \epsilon$ in Water-Moderated Slightly Enriched $U$ and $\mathrm{UO}_{2}$ Lattices", Nuclear Science and Engineering, 3 (4) (April, 1958).

(2) Volpe, et al.., "Two Region Studies in Slightly Enriched Water-Moderated U and UO 2 Lattices", Nuclear Science and Engineering, $\underline{5}$ (6) (June, 1959).

(3) Weinberg, A. M., and Wigner, E. P., The Physical Theory of Neutron Chain Reactors, University of Chicago Press, $\frac{(1958), \mathrm{p} 314 .}{}$

(4) Davis, M. V., "The Dopplex Coefficient of U235 Fuel Elements", Nuclear Science and Engineering, 3 (1) 167, (January, 1958).

(5) Schroeder, F., et al., "Experimental Study of Transient Behavior in a Sub-Cooled Water-Moderated Reactor", Nuclear Science and Engineering, $\underline{2}$ (1) 96-115

(February, 1957). 
(6) "Summary Report on the Reactor Hazards Associated With the Danger Coefficient Test Facility (DCTF)", TID-10052, pp 120-121 (April 30, 1951).

RAE:WSH:DAD:JWC/nb 


$$
=
$$




$$
A-1
$$

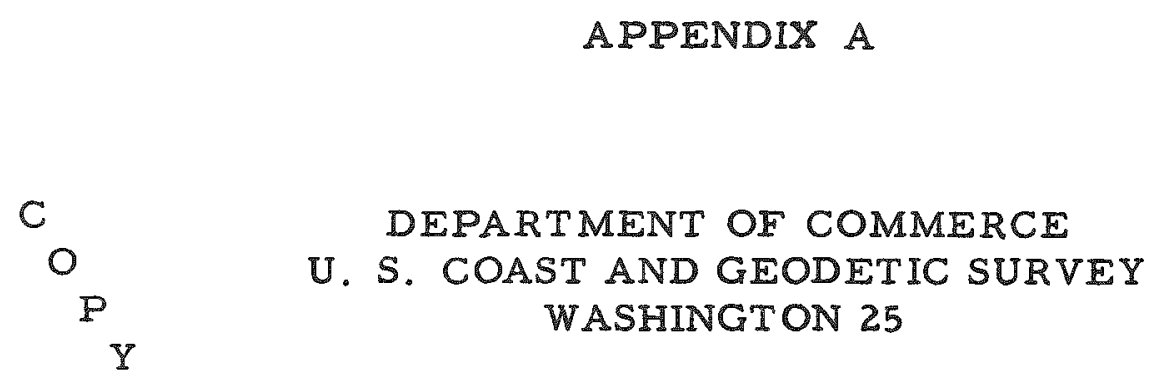

August 24, 1954

Mr. James N. Anno, Jr.

Battelle Memorial Institute

$505 \mathrm{King}$ Avenue

Columbus 1, Ohio

Dear Sir:

Replying to your request of August 19, 1954, we find no record of earthquakes having occurred in West Jefferson, Ohio, and immediate vicinity. However, as Rev. V. C. Stechschulte stated, there have been several minor earthquakes in western Ohio. Among the most noteworthy are the following which are briefly described in SP 609, Part 1, Earthquake History of the United States.

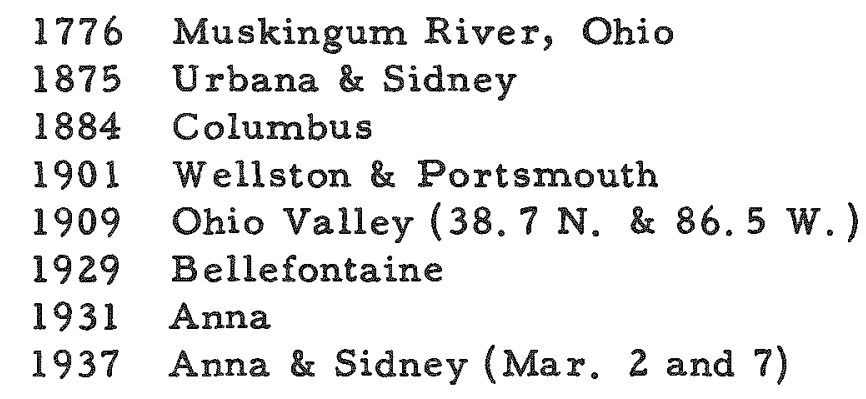

If we may be of further service please do not hesitate to write again.

Very truly yours,

/s/ Robert W. Knox

Acting Director

Enclosure 
C<smiles>[Y]PO</smiles>

Mr. Jim Anno

Battelle Memorial Institute

Columbus, Ohio

Dear Mr. Anno:

This is in reply to your telephoned request of yesterday afternoon.

The problem of determining seismic risk in a given area is largely a guessing game. All that can be done is to list the earthquakes, with the damage done, that have occurred there within the comparatively few years of our historical record, and then to say that where earthquakes have occurred in the past, they may more likely occur again in the future rather than in places where there has been no seismic record.

The catalogs that would be pertinent to your purpose would be:

Serial 609, Earthquake History of the U. S., Part I (pp 39-46). Serial No. 511, United States Earthquakes, 1929 (p. 8)

Serial No. 553, " " " 1931 (p. 7)

Serial No. 619, " " $" 1937$ (p. 8, 9).

These will give you more detail than is indicated by the maps, listing places where the earthquakes were felt and where damage may have been reported. What it will all add up to is that there has been minor damage approximately within the 50-mile circle with more severe damage in a small area around Anna, Ohio. The small earthquake in the vicinity of Zanesville two or three years ago would make no significant change in the picture.

Sincerely yours,

V. C. Stechschulte, S. J.

(Rev.) V. C. Stechschulte, S. J. Director of the Seismological Observatory 
APPENDIX B

METEOROLOGY REPORT 


\section{APPENDIX B}

\section{METEOROLOGY REPORT}

\section{Introduction}

The purpose of this report is to review the meteorology of the Columbus, Ohio, area for use in the site evaluation and compilation of a hazards analysis.

\section{Source of Data}

Although no meteorological data exist for the proposed site itself, very complete meteorological records have been taken for many years at several locations in Columbus. There does not appear to be any significant difference in the general topography of the area between the site and Columbus, so, for most purposes, the meteorological data which have been previously collected should be adequate for this preliminary evaluation. The Local Climatological Data* for Columbus, Ohio, presents a good general description of the weather of this area. The table headed Normals, Means and Extremes on page 2 of this annual summary presents average data on temperature, degree days, precipitation, snow, humidity, wind, etc.

\section{Climatological Review}

In the present brief report, those meteorological parameters will be stressed which influence directly the spread of atmospheric wastes.

\section{Surface Wind Direction}

The hourly wind observations for a 6-year period, 1948-1953, for the Weather Bureau Airport Station (WBAS) at Columbus were studied in detail. Table B-1 presents the percentage frequency of the wind direction. The prevailing wind direction is from the southerly quadrant (41 per cent of winds blow from the general direction $S E$ through $S W$ ). The secondary prevailing direction is from the NW. There does not appear to be any major change in

- U.S. Department of Commerce, Weather Bureau, "Local Climatological Data", for 1953, Columbus, Ohio, U. S. Government Printing Office, price 10 cents. 
TABLE B-1. PERCENTAGE FREQUENCY OF WIND DIRECTION, WEA THER BUREAU AIRPORT STATION, COLUMBUS, OHIO

(Based on hourly observations January, 1943, through December, 1953)

\begin{tabular}{|c|c|c|c|c|c|c|c|c|}
\hline $\begin{array}{c}\text { Wind } \\
\text { Direction }\end{array}$ & Winter & Spring & Summer & Fall & $\begin{array}{c}\text { Annual } \\
\text { (A11 } \\
\text { Observations) } \\
\end{array}$ & $\begin{array}{c}\text { Annual } \\
(8 \mathrm{am}-4 \mathrm{pm})\end{array}$ & $\begin{array}{c}\text { Annual } \\
(5 \mathrm{pm}=7 \mathrm{am})\end{array}$ & $\begin{array}{l}\text { Annual } \\
\text { (Only When Precipi- } \\
\text { tation Was Occuring) }\end{array}$ \\
\hline $\mathbb{N}$ & 3.9 & 5.7 & 6.9 & 4.5 & 5.3 & 4.5 & 5.8 & 4.3 \\
\hline NNE & 2.4 & 3.8 & 4.0 & 3.0 & 3.3 & 3.0 & 3.5 & 2.7 \\
\hline NE & 3.2 & 3.7 & 4.7 & 2.9 & 3.6 & 3.1 & 4.0 & 2.9 \\
\hline ENE & 2.9 & 3.4 & 3.0 & 2.6 & 3.0 & 2.6 & 3.1 & 2.8 \\
\hline $\mathbb{E}$ & 3.8 & 4.9 & 4.9 & 4.2 & 4.5 & 3.4 & 5.1 & 3.3 \\
\hline $\mathbb{E S E}$ & 4.2 & 4.0 & 3.4 & 3.6 & 3.8 & 2.5 & 4.6 & 4.2 \\
\hline SE & 9.0 & 8.3 & 9.9 & 11.0 & 9.5 & 7.0 & 11.1 & 8.9 \\
\hline SSE & 8.4 & 5.2 & 7.5 & 8.7 & 7.4 & 6.5 & 8.0 & 6.9 \\
\hline s & 10.8 & 7.6 & 9.2 & 10.5 & 9.5 & 10.8 & 8.7 & 8.4 \\
\hline SSW & 9.6 & 7.4 & 7.0 & 8.2 & 8.0 & 11.4 & 6.0 & 9.6 \\
\hline SW & 6.8 & 7.4 & 6.6 & 7.0 & 7.0 & 10.6 & 4.7 & 7.6 \\
\hline WSW & 4.7 & 5.0 & 2.8 & 3.5 & 4.0 & 5.1 & 3.4 & 5.4 \\
\hline W & 4.5 & 4.6 & 1.8 & 2.8 & 3.4 & 4.1 & 3.0 & 4.8 \\
\hline
\end{tabular}


TABLE B-1. (Continued)

\begin{tabular}{|c|c|c|c|c|c|c|c|c|}
\hline $\begin{array}{l}\text { Wind } \\
\text { Direction }\end{array}$ & Winter & Spring & Summer & Fall & $\begin{array}{c}\text { Anuual } \\
\text { (All } \\
\text { Observations) }\end{array}$ & $\begin{array}{c}\text { Anmual } \\
(8 \mathrm{am}-4 \mathrm{pm})\end{array}$ & $\begin{array}{c}\text { Annual } \\
(5 \mathrm{pm}-7 \mathrm{am})\end{array}$ & $\begin{array}{l}\text { Annual } \\
\text { (Only When Precipi } \\
\text { tation Was Dccurring) }\end{array}$ \\
\hline WNW & 7.5 & 7.1 & 3.8 & 5.2 & 5.9 & 6.7 & 5.5 & 8.6 \\
\hline NW & 9.8 & 10.9 & 8.3 & 9.1 & 96 & 9.8 & 9.4 & 11.2 \\
\hline NNW & 6.1 & 7.6 & 8.0 & 7.4 & 7.3 & 7.4 & 7.3 & 6.8 \\
\hline Calm & 2.4 & 3.4 & 8,1 & 5.7 & 4.9 & 1.6 & 6.9 & 1.3 \\
\hline
\end{tabular}


wind-direction frequency from season to season except that northwesterly winds predominate in the Spring, while the south and southeast winds reach their maximum frequcncy in the fall. Table $B-1$ also compares the wind frequencies for two periods of the day -8 am to $4 \mathrm{pm}$ and $5 \mathrm{pm}$ to $7 \mathrm{am}$. From a study of these data, it is clear that no large diurnal change in the wind direction should be expected on the average, although night-time conditions favor southeasterly directions and calms, whereas the prevailing daytime wind is south-southwest.

It is necessary to examine the wind structure during periods of precipitation in order to consider the effect of wash-out of possible waste contaminants. Table $B-1$ also presents the percentage frequency of wind directions at Columbus during those hours when precipitation was falling. (This was approximately 15 per cent of the time.) In this case, also, there does not appear to be any major shift in the prevailing wind direction frequencies, although $\mathrm{NW}$ is the primary maximum in this case.

Wind direction is also important when the lower atmosphere is very stable and atmospheric diffusion is at a minimum. From other meteorological studies of this correlation (Cincinnati, Dayton, and Detroit), it seems probable that the most stable weather in the Columbus area would accompany the southerly and southeasterly winds. The northwesterly winds would be associated with unstable or good diffusion atmospheric conditions. This tendency is borne out by the seasonal and diurnal variations, spring and daytime being the periods in which low-level instability is most common.

\section{Surface Wind Speed}

Table B-2 presents the percentage frequency of wind speeds in various class intervals. There is a striking persistency to the distribution. Approximately 58 per cent of the winds in the Columbus area will occur in the 4 to $12-\mathrm{mph}$ speed interval. The average speed is $8.4 \mathrm{mph}$, although it is slightly weaker in the summer months and stronger in the winter. Winds less than $4 \mathrm{mph}$ occur approximately 21 per cent of the time on the average (10 per cent during the day, 28 per cent during the night, and 10 per cent during those hours when precipitation is occurring). During a 51-year period in Columbus, peak wind speeds have been observed to exceed $51 \mathrm{mph}$ during every month of the year. The highest recorded speed was $84 \mathrm{mph}$ during July.

Two very localized types of storms which are accompanied with high wind speeds deserve special mention - thunderstorms and tornadoes. Thunderstorms occur on the average of 41 days per year, primarily in the late spring and summer, although they have occurred during every month of the year. The peak activity is in June and July. These months average 8 thunderstorm days apiece. Thunderstorm activity is extremely variable, 
TABLE B-2. PERCENTAGE FREQUENCY OF WIND-SPEED GROUPS, WEATHER BUREAU AIRPORT STATION, COLUMBUS, OHIO

(Based on hourly observations January, 1948, through December, 1953)

\begin{tabular}{|c|c|c|c|c|c|c|c|c|}
\hline $\begin{array}{l}\text { Wind } \\
\text { Speed. } \\
\text { mph }\end{array}$ & Winter & Spring & Summer & Fall & $\begin{array}{c}\text { Annual } \\
\text { (All } \\
\text { Observations) } \\
\end{array}$ & $\begin{array}{c}\text { Annual } \\
(8 \mathrm{am}-4 \mathrm{pm})\end{array}$ & $\begin{array}{c}\text { Anmua } \\
(5 \mathrm{pm}-7 \mathrm{am})\end{array}$ & $\begin{array}{l}\text { Annual } \\
\text { (Only When Precipi- } \\
\text { tation Was Occurring) }\end{array}$ \\
\hline Calm & 2.4 & 3.4 & 8.1 & 5.7 & 4.9 & 1.6 & 6.9 & 1.3 \\
\hline $1-3$ & 12.0 & 11.9 & 23.4 & 17.7 & 16.2 & 8.9 & 20.6 & 8.5 \\
\hline $4-12$ & 57.9 & 56.2 & 59.0 & 57.6 & 57.6 & 57.2 & 57.9 & 55.0 \\
\hline $13-24$ & 27.0 & 27.8 & 9.8 & 18.8 & 20.8 & 31.5 & 14.3 & 34.2 \\
\hline $25-31$ & 0.7 & 1.0 & (a) & (a) & 0.5 & 0.7 & 0.4 & 0.9 \\
\hline $32-46$ & (a) & (a) & (a) & (a) & (a) & (a) & (a) & (a) \\
\hline $\begin{array}{l}\text { Mean } \\
\text { wind } \\
\text { speed }\end{array}$ & 9.7 & 9.7 & 6.4 & 7.9 & 8.4 & 10.5 & 7.1 & 10.8 \\
\hline
\end{tabular}

(a) Only a few observations. 
but a zare severe storm may cause winds in excess of $50 \mathrm{mph}, 1$ to 3 in. of rain in an hour, and hailstones $1 / 2$ in. or larger in diameter. Situations favorable for the formation of severe thunderstorms are also conducive to tornado formation. However, this more violent storm is rare in the Columbus area. A 35-year study of United States tornadoes shows that 111 tornadoes occurred in Ohio during this period, with the largest percentage of these storms in the northern and western portions of the state. Local storm records from 1931 through 1954 show only four tornadoes in the immediate Columbus area.

\section{$\underline{\text { Precipitation }}$}

The Columbis area receives approximately $38 \mathrm{in}$. of precipitation annually, which is spread over approximately 140 days. Precipitation is distributed rather evenly throughout the year with the maximum occurring in the late spring and early summer. The maximum amount of precipitation ever observed in 24 hr was 3.91 in. Columbus has an average snowfall of 22 in., which falls on approximately 6 days per year. The greatest amount ever recorded for a $24-\mathrm{hr}$ period was 11.9 in., and for 1 month was 29.2 in.

\section{Atmospheric Stability}

Measurements of the vertical temperature distribution are not made in the Columbus area. However, measurements made at other locations have shown a high degree of correlation between low winds periods, restricted visibility, and the occurrence of inversions. Conversely, high wind speeds and good visibility are indicative of lapse conditions and good diffusion weather. The Columbus area experiences approximately 15 days on which a heavy fog occurs for a few hours. Visibility is reduced to below 6 miles approximately 43 per cent of the hours annually. For just fog, it is reduced to below 6 miles approximately 8 per cent of the time.

Inversions form nearly every night, but there is nothing in the records which could be interpreted to signify that the Columbus area experiences an unusual amount of poor atmospheric stability conditions. 


\section{APPENDIX C}

CONCLUSIONS OF GEOLOGY AND HYDROLOGY REPORT 
APPENDIX C

\section{CONCLUSIONS OF GEOLOGY AND HYDROLOGY REPORT}

The conclusions of a report on the geology and hydrology of the Battelle site are reprinted here. This report appears in full in a previous hazards report on the critical assembly. **

"The Battelle site seems to be almost entirely safe for the operation of a nuclear power reactor, with respect to the effects on the ground water resources resulting from accidental spillage of radioactive fluids in the site area. In the event of a spill, most of the liquid would flow overland to Darby Creek. Only a small portion would infiltrate the soil and seep downward to the water table or reach the principal artesian aquifer.

"Infiltration would be greatest when the soil is dry, especially during periods of large soil moisture deficiency, such as would occur during the growing season. Conditions least favorable for infiltration, and those which would promote most rapid runoff, would result from frozen or saturated ground, or would occur during a heavy rainstorm when a large volume of water is flowing overland towards Darby Creek.

"The course of a spilled liquid, once it reached the water table, also would be towards Darby Creek where it would discharge into the stream through springs and seeps. The shallow aquifer is unimportant as a source of water in the site area and the chances are almost nil under present conditions that a contaminant introduced into the shallow aquifer on the Battelle property would be diverted to wells or otherwise intercepted by man in the course of its slow underground journey to the discharge area.

"A greater chance for contamination of ground water supplies would result from radioactive fluid entering the principal aquifer in the site area. This danger is slight, however, for the principal aquifer receives most of its recharge in upland areas some distance west of the Battelle site. Only a relatively small amount of water percolates through the till to reach the principal aquifer in the immediate area of the site. Moreover, a contaminant reaching the principal aquifer in the immediate area of the Battelle property would already be down-gradient from almost all the wells in the area.

\footnotetext{
Norris, Stanley, "Hydrology of a Proposed Reactor Site Near Columbus, Ohio", U. S. Geological Survey, Water Resources Division, Columbus, Ohio (August, 1954).

BMI-ACRS -600 .
} 


$$
\mathrm{C}-2
$$

"Practically the only potential danger of contamination to a specific ground water supply is to the supply now being developed by the Battelle Memorial Institute near the southeast corner of their property. Pumping from the well now being drilled, and from possible future wells, would lower ground water levels in the principal aquifer in the immediate area of the wells. This would induce more recharge locally from the overlying till by creating a cone of influence which might encompass areas where the danger of contamination would be greatest. In view of this possibility a careful record should be maintained of the natural radioactivity of the water from the Battelle plant wells, to be used as a basis for comparison to detect any contamination should spillage occur.

"The greatest danger to human life and property resulting from spillage of radioactive fluid in the Battelle site area would be for the fluid to reach Darby Creek in volume and to move downstream in toxic concentration. Darby Creek is not now used either as a source of public or of large-scale industrial water supply, though it undoubtedly will be used eventually for both purposes. It is however, an important source of water for stock all along its course and it flows into the Scioto River above several important water supply developments, including the supply for the Atomic Energy Commission plant in Pike County.

"The velocity of flow in Darby Creek ranges from very low, when the stream is in pool stage and the only perceptible flow is over the riffles, to very high when the stream is in flood. The velocity of flow is important to any further evaluation of the fate of a spilled liquid once it reaches the stream and it should be studied under various conditions of discharge. Surface water samples should be collected and analyzed to determine the natural radioactivity of the stream, and the records maintained as a basis for future comparison." 
APPENDIX D

COMMENTS ON THE USE OF FURFURYL ALCOHOL AND FURFURAL IN CRITICAL-ASSEMBLY RESEARCH 
COMMENTS ON THE USE OF FURFURYL ALCOHOL AND FURFURAL IN CRITICAL-ASSEMBLY RESEARCH

In critical-assembly studies of boiling-water reactors the important effects of voids must be evaluated. In the laboratory, it is desirable to operate the experiment under atmospheric conditions. To provide good simulation at low temperature and pressures requires a material with the properties of low-density water. Several possibilities present themselves. For example, balloonlike objects may be inflated at prescribed locations throughout the core to simulate voids or a solid such as foamed polyethylene can be used. Alternately, a liquid other than water may be used. Each method has application for special cases. In measuring the reactivity effect of a small localized void where the effect of a sudden rupture is not catastrophic inflatable devices are acceptable. A boiling reactor in which the parameters are fixed may be simulated economically using foamed polyethylene. However, this method is not economically feasible where many boiling configurations requiring specially machined moderator components are required.

The third method, using liquids having a lower hydrogen density than water at room temperature, has been selected for the present research. The use of polyethylene would roughly double the cost of the experiments and collapsible voids are hazardous when used to simulate cores with large void fractions.

Before selecting furfuryl alcohol and furfural a great variety of liquids were screened on the basis of two criteria: (1) the liquid must have a hydrogen density comparable to that of water containing voids up to about 60 per cent by volume and (2) the liquid must be relatively inexpensive and safe to handle. These restrictions eliminated many more exotic liquids and led to the choice of furfuryl alcohol and furfural. Pertinent physical properties of the liquids are listed in Table D-1.

Use of furfuryl alcohol and furfural in critical-assembly research has been considered in detail from three viewpoints: (1) combustion hazards associated with these liquids, (2) biological hazards, and (3) special chemical and nuclear properties. The following sections pertain to the se three items.

\section{Combustibility Properties of Furfuryl Alcohol and Furfural}

In storing and handling furfuryl alcohol and furfural one must consider the possibility of fire. Both liquids are flammable if raised to about $740 \mathrm{~F}$, their ignition temperatures. Their flammability is comparable to kerosene or No. 1 fuel oil. Thus, in storage container at room temperature the vapor pressure is below the critical value required to form an ignitible mixture (note the open-cup flash points). The major fire hamard appears to be in handing the liquids since clothing or other absorbent materials may act as "wicks". Then the liquid may be ignited by raising its temperature to a value where the vapor pressure is above the minimum value required to sustain burning, about 250 For both furfuryl alcohol and furfural. 
TABIE D-1. COMPARISON OF PHYSICAL CONSTANTS OF FURFURYL ALCOHOL AND FURFURAL WITH WATER(a)

\begin{tabular}{|c|c|c|c|}
\hline Property & $\begin{array}{l}\text { Furfuryl } \\
\text { Alcohol }\end{array}$ & Furfural & Water \\
\hline Specific Gravity at $20 \mathrm{C}$ & 1.1285 & 1.1598 & 1.00 \\
\hline Molecular Weight & 98.1 & 96.08 & 18.0 \\
\hline Specific Heat at $25 \mathrm{C}, \mathrm{cal} /(\mathrm{g})(\mathrm{C})$ & 0.502 & 0.416 & 1.00 \\
\hline Thermal Conductivity, Btu/(hr) $(f t)(F)$ & -- & 1.525 & 0.34 \\
\hline Flash Point, Open Cup, F & 167 & 152 & -- \\
\hline Autoignition Temperature, $F$ & 735 & 740 & - \\
\hline \multicolumn{4}{|l|}{ Explosion Limits, 72.5 to $122 \mathrm{C}$ : } \\
\hline \multicolumn{4}{|l|}{ Per cent by Volume in Air } \\
\hline Lower Limit & 1.8 & 2.1 & -- \\
\hline Upper Limit & 16.3 & $\begin{array}{l}\text { Not } \\
\text { available }\end{array}$ & -- \\
\hline Heat of Combustion, cal per $g$ & 6206 & 5830 & -- \\
\hline $\begin{array}{l}\text { Hydrogen Density/Hydrogen Density of Water } \\
\text { at } 20 \mathrm{C}\end{array}$ & 0.62 & 0.43 & 1.00 \\
\hline Vapor Pressure at $20 \mathrm{C}$, mm per $\mathrm{g}$ & $<1$ & $<1.0$ & 76 \\
\hline
\end{tabular}

(a) See Reference (1) at the end of this Appendix.

The following procedures worked out in conjunction with the Battelle Safety Office will be adopted to minimize the fire hazard.

(1) The coolant region of the reactor will be purged with carbon dioxide gas before each run and an automatic $\mathrm{CO}_{2}$ fire extinguishing system will be installed at the core location.

(2) No smoking or other form of fire will be permitted in the criticalassembly room. (This rule has always been in effect.)

(3) Sources of electric sparks such as control-rod drives, liquidlevel-measuring mechanisms, and neutron-source drives will be located around the reactor with consideration for the fire hazard. 
(4) Personnel will be instructed in handling these liquids and in personal haluil cuncerning possible formation of "wicks".

The fire hazard associated with these liquids is best summarized by noting that no ICC precautionary labels are required for shipping them.

\section{Biological Hazards}

Furfuryl alcohol and furfural are mildly toxic if taken internally and are injuxious to flesh. No operation in the research program will cause the liquids to be imbibed accidentally. Special watertight gloves will be employed for handling the fuel pins after they have been in contact with the se liquids. The laboratory is equipped with two stall showers in the event any personnel have accidental physical contact with the liquids.

\section{Special Chemical and Nuclear Properties}

Furfuryl alcohol and furfural react violently with some acids and with certain uncommon chemicals. Milder chemical-combination reactions occur with a variety of carbohydrates including many plastics, resins, coatings, etc. These chemical properties are quite well known and it can be said with certainty that the se liquids will be inert in combination with all materials used in the reactor. Polymerization of furfuryl alcohol and furfural occurs during storage and is accelerated by increasing temperature by oxidation and by dilution with water (probably a result of an increased oxygen environment). Polymerization which proceeds without liberating combustible(1) gases does form insoluble polymers which can alter the composition of the liquids and coat the surface of containers and piping. However, a 0.3 per cent $n$-butylamine solution has been found effective in inhibiting polymerization. The liquids will also be replenished regularly and, hence, storage time of a particular batch will be about 2 months. Small changes in physical properties, such as viscosity, etc., which accompany chemical instability during storage are not considered important to the present studies.

Furfuryl alcohol has been used in previous critical-assembly research without incident(2), with the precautions similar to those given above. These precautions are probably more for the protection of equipment and personnel than for safeguarding against a nuclear accident.

The radiation stability of furfuryl alcohol and furfural have not been studied extensively. It has been reported(3) that no effect was noted up to an absorbed dose of $10^{6}$ rep. This is far in excess of the planned integrated experimental irradiation.

\section{REFERENCES}

(1) Dunlop, A. P., and Peters, F. N. The Furans, Reinhold Publishing Corporation, New York (1953). 


$$
\mathrm{D}-4
$$

(2) Jankowski, F. M. Klein, D., and Miller, T. M., "Experiments With Furfuryl Alcohol in a Critical Assembly", Nuclear Science and Technology, Vol 2, No. 3, 237-248 (December, 1956). Secret.

(3) Carleton, L. T., et al., Aerojet-General Nucleonics, Quarterly Progress AF Contract 33(616)-3726, October 1956-January 1957 (February, 1957). 
APPENDIX E

OPERATIONAL AND LABORATORY RULES 


\section{APPENDIX E}

\section{OPERATIONAI AND ILABORATORY RUIES}

The following critical-assembly and laboratory operating rules have been distributed to all persons directly associated with the VMR critical experiments. In addition, these rules are posted in the critical-assembly control room.

\section{Critical-Assembly Operational Rules}

On days of reactor operation these rules must be followed unless written permission for exceptions are posted with this notice.

(1) Three people familiar with the facility to be operated or with reactor operation in general must be present during operation. Two of these must be qualified operators of the particular facility being operated.

(2) Established checkout procedures must be followed and a check list signed off on operating days.

(3) A minimum of three power levels and one period scram is to be in operation.

(4) There must be a visual indication of power level on at least two instruments while approaching critical.

(5) Reactivity must not be changed faster than 0.04 per cent per sec. Mechanical and electrical controls are to be adjusted to meet this condition.

(6) Outside doors in the critical-assembly room are to be locked and sealed during operation.

(7) All operators must be in agreement before proceeding with an experiment.

(8) Data on which operating decisions are to be made must be plotted.

(9) Each person assigned to the project and present in the control room during an experiment must be engaged in activities which are directly connected with the current operation.

(10) The doors dividing the control room, vault, and critical-assembly room from the rest of the building must be locked during any experiments.

(11) Radiation warning signals must be posted prior to any reactor experiments. 


\section{Critical-Assembly Laboratory Rules}

To be followed at all times unless written permission for exceptions are posted with this notice.

(1) No core will be assembled which will go critical by operating rods alone.

(2) Anytime fuel is handled in the critical-assembly room a physicist familiar with the handling procedures must be present.

(3) Anytime the vault is open a physicist familiar with fuel-handling procedures must be present.

(4) There is to be a minimum of two physicists present at any time the assembly room or vault is open.

(5) No one is to be in the assembly room when the reactor halves are assembled or water is in a reactor tank. When people are in the assembly room the reactor tables are not to be moved more than 6 in. from their full-out position or water is not to be pumped into a reactor tank.

(6) A detailed written plan of each experiment is to be presented to the scientist in charge and approved before changes are made in the reactor or criticality is attempted.

(7) No fuel additions or rearrangements are to be made without adequate checks on the multiplication.

(8) No flammable liquids or gases are to be left in the assembly room or vault unattended.

(9) Security personnel are not to enter the assembly room or vault to fight fires unless a physicist of the operating crew is present. 


\section{APPENDIX F}

ANALYSIS OF RAMP REACTIVITY ADDITION 


\section{APPENDIX F}

\section{ANALYSIS OF RAMP REACTIVITY ADDITION}

The instantaneous period and power level ratio were estimated for the allowable linear addition rate of 0.04 per cent $\Delta k \mathrm{k}$ per sec. This estimate was made by approximating the linear rate by a series of equal step additions and finding the resulting period and power level. The results of this estimate are shown in Figure F-1. It can be seen from this figure that the period trip will scram the reactor about 10 sec after initiating the ramp function, and that the power level at this time is about 2.5 times the initial level. If the period circuits should fail, a power level trip would scram the reactor at $14 \mathrm{sec}$ after starting to add reactivity and the period would be about 0.75 sec. 


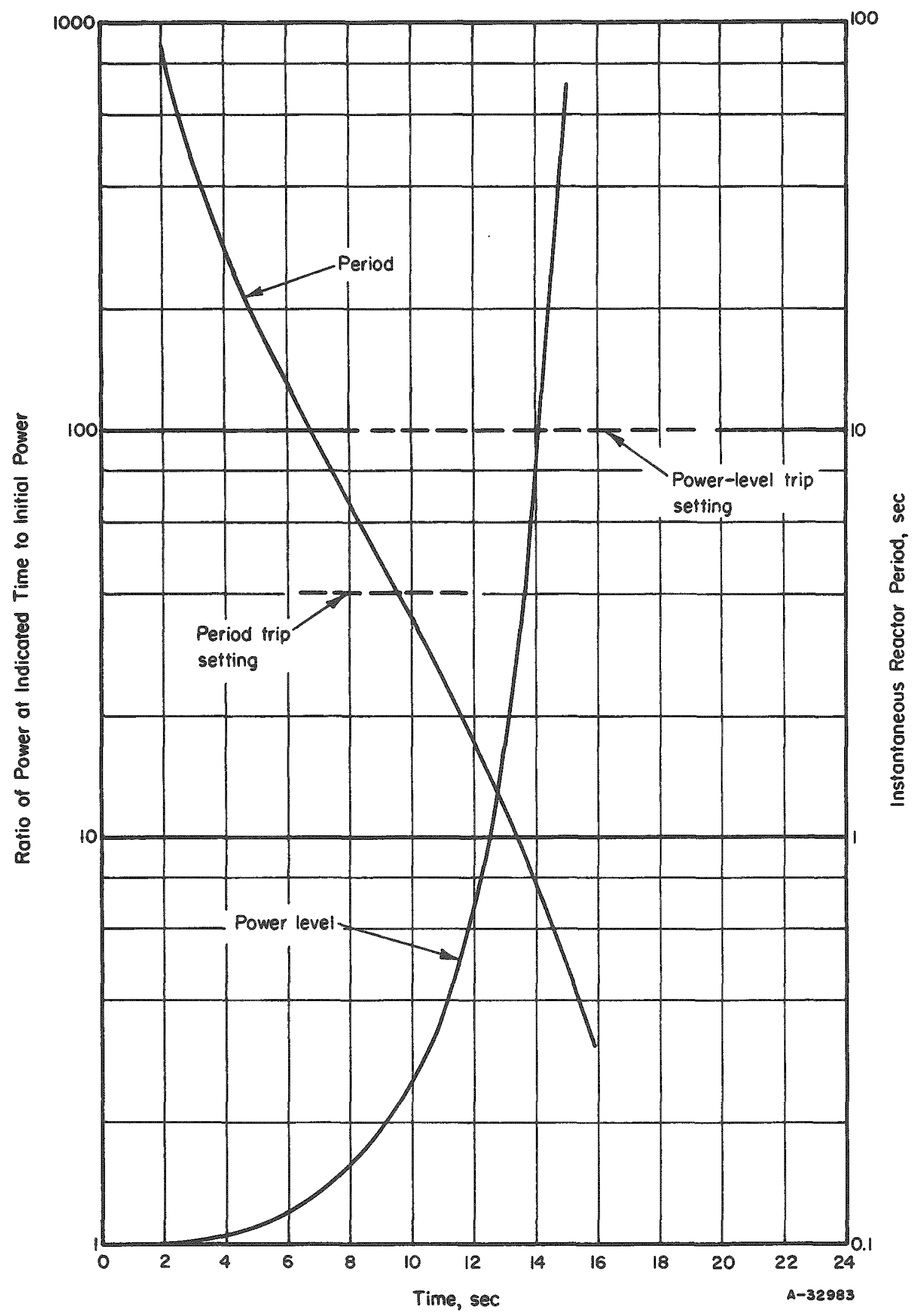

FIGURE F-1. INSTANTANEOUS REACTOR POWER AND PERIOD FOR A LINEAR REACTIVITY INSERTION OF $0.0004 \triangle \mathrm{k} / \mathrm{K}$ PER SEC 